\title{
BILE SALTS- AND FERRIC IRON-INDUCED PMRAB \\ DEPENDENT RESISTANCE TO CAMPS IN EHEC O157:H7
}

\author{
by \\ Aju-sue Francis \\ Bachelor of Science (Hons.), Ryerson University, 2014
}

A thesis presented to Ryerson University

in partial fulfillment of the requirements for the degree of Master of Science

in the program of Molecular Science

Toronto, Ontario,

Canada, 2017

(C) Aju-sue Francis, 2017 


\section{AUTHOR'S DECLARATION FOR ELECTRONIC SUBMISSION OF A THESIS}

I hereby declare that I am sole author of this thesis. This is a true copy of the thesis, including any required final revisions, as accepted by my examiners.

I authorize Ryerson University to lend this thesis to other institutions or individuals for the purpose of scholarly research.

I further authorize Ryerson University to reproduce this thesis by photocopying or by other means, in total or in part, at the request of other institutions or individuals for the purpose of scholarly research.

I understand that my thesis may be made electronically available to the public. 


\title{
BILE SALTS- AND FERRIC IRON-INDUCED PMRAB DEPENDENT RESISTANCE TO CAMPS IN EHEC O157:H7
}

\author{
Aju-sue Francis \\ Master of Science \\ Molecular Science
}

Ryerson University, 2017

\begin{abstract}
Enterohaemorrhagic Escherichia coli 0157:H7 (EHEC) colonization of the gastrointestinal tract is critically dependent on its ability to sense and respond to the external environment. This research aims to evaluate the contribution of bile salts- and ferric iron-induced resistance in EHEC to cationic antimicrobial peptide (CAMP) and the roles of pmrAB and arn operon in these events. Results showed that EHEC, treatment with either bile salts or ferric iron induced a dose-dependent resistance to Polymyxin B. This resistance phenotype was lost in each of the pmrA and pmrB mutants. PMB resistance in EHEC was also dependent on the concentration of magnesium and on $\mathrm{pH}$, suggesting the involvement of another two component system, PhoPQ. Mutagenesis of the iron-binding site of PmrB abrogated the induced resistance phenotype. The results of this study provide novel insights critical for our understanding of the molecular basis of pathogenesis and may provide new insights toward prevention strategies.
\end{abstract}




\section{Acknowledgements}

First and foremost, I would like to thank my supervisor, Dr. Debora Foster, who supported me throughout my thesis with guidance and support, which allowed me to persevere at times when the possible seemed impossible. Dr. Foster provided her help and knowledge that contributed to the accomplishment of my work.

I am very thankful for my lab mates, Tracy Lackraj, Crystal Gadisahw-Lue, Alyssa Banaag, Sarah Birstonas, Michele Kacori, Piravena Sabesan, and Veronica Cojocari who helped me to be successful in my work.

Lastly, I would also like to thank my immediate friends, Homai Anvari, Victoria Hipolito, Philip Junor, Sami Boubertakh, Chantau Muir, Jennifer Seedu, Natasha Ash, Shanice Benjamin and Stefan Plowell for all their support. As well as my mother, Arlene Wilson, who has continually supported me throughout the years and helped me in any way she could. They gave me the drive to complete this project and made this process an enjoyable experience. 
$\underline{\text { Table of Contents }}$

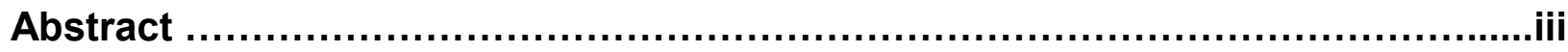

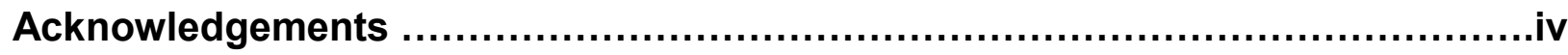

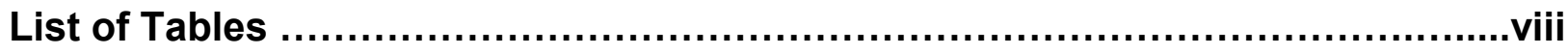

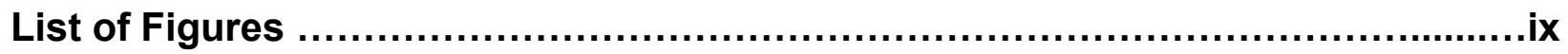

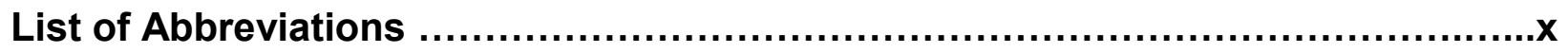

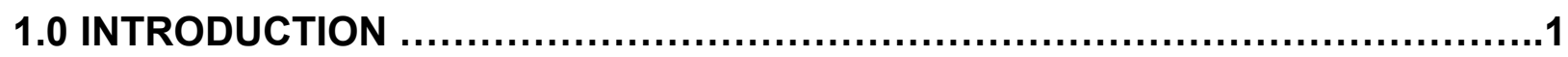

1.1 Enterohemorrhagic Escherichia coli ..........................................

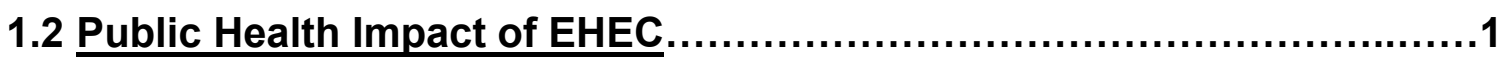

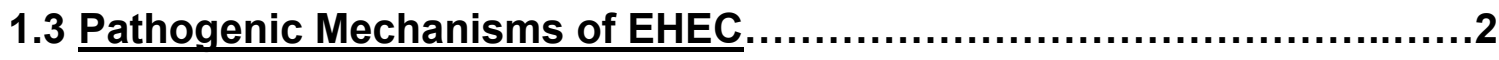

1.4 Role of host environmental stress on EHEC fitness \& infection

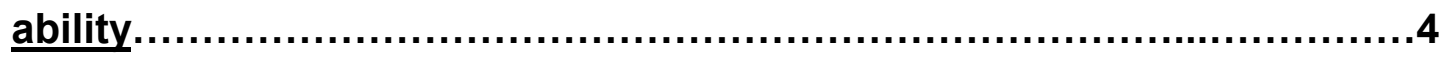

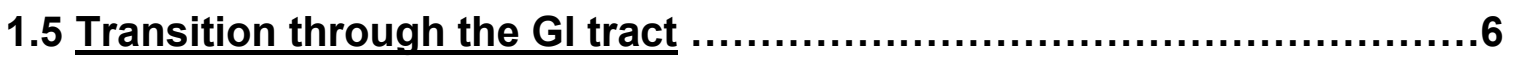

1.5.1 The Composition and Function of Bile ............................

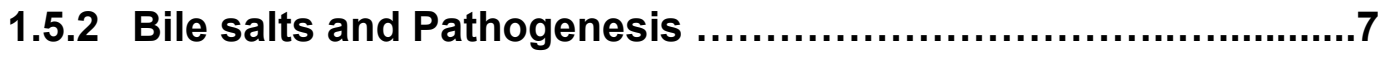

1.5.3 Ferric Iron and Pathogenesis.....................................

1.5.4 Host evasion strategies ............................................ 10

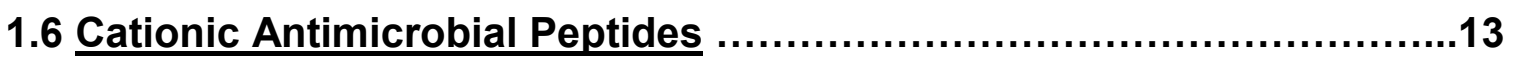

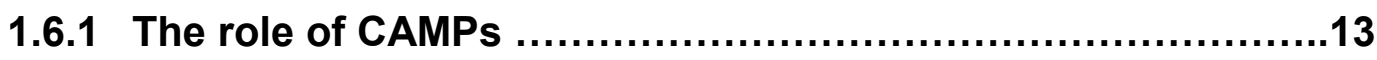

1.6.2 EHEC resistance to Cationic Antimicrobial Peptides ............14

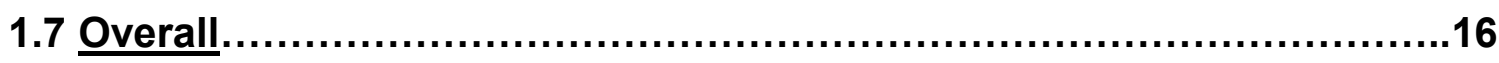




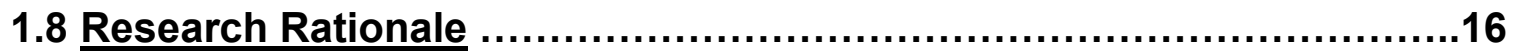

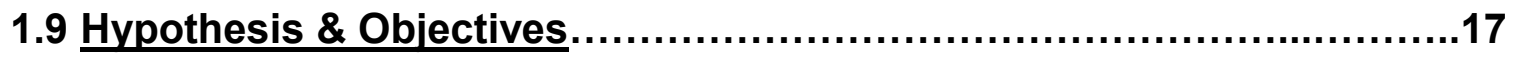

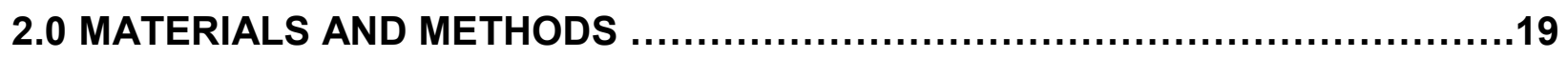

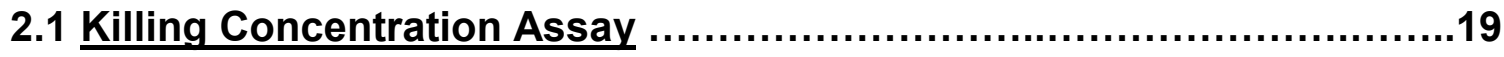

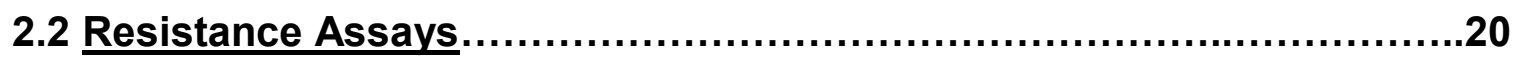

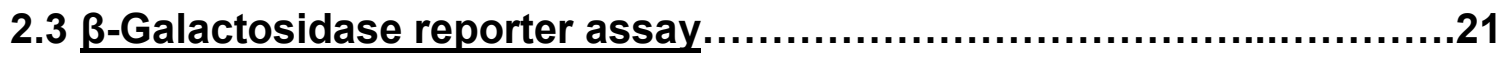

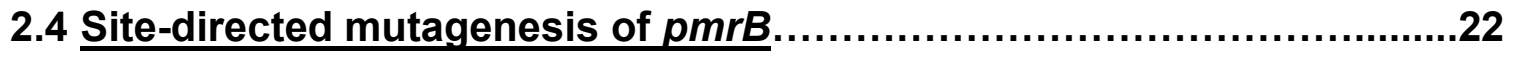

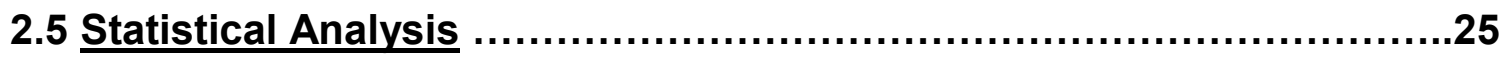

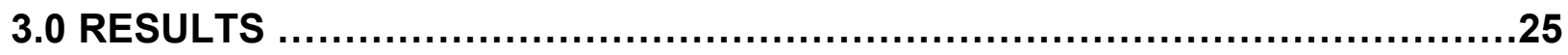

3.1 Determination of Ferric iron Toxicity level for EHEC ............................26

3.2 Killing concentration of PMB for EHEC 86-24I..........................28

3.3 Role of pmrA and pmrB in survival after PMB challenge...................30

3.3.1 The Relative Roles of pmrA and pmrB in PMB

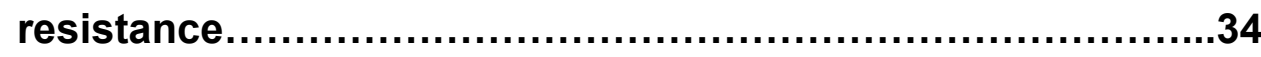

3.4 Bile salts- and Ferric iron-induced resistance to PMB $\ldots \ldots \ldots \ldots \ldots \ldots . . . \ldots . \ldots . \ldots$

3.5 Promoter activity of pmrAB operon and arn BCADTEF in response to bile salts and ferric iron treatment...........................................38

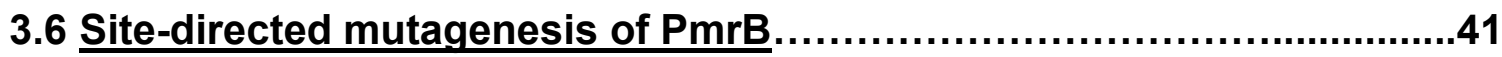

3.7 PmrAB and PhoPQ modulation in EHEC ....................................43

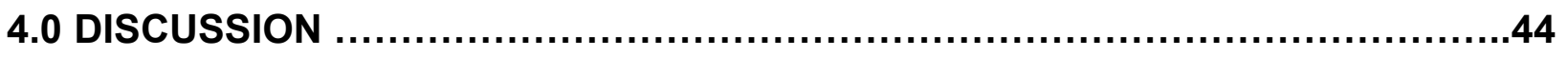

4.1 Killing Concentrations of PMB higher under modulating conditions of

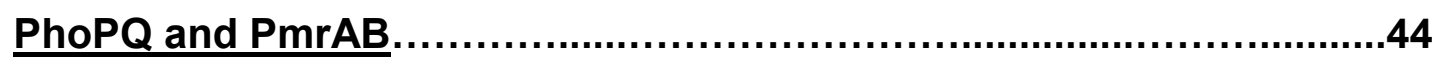


4.2 Killing concentration of ferric iron largely dependent on pH. .45

4.3 PmrAB plays an important role in EHEC's resistance to PMB 46

4.4 Bile salts and Ferric Iron induce PMB resistance in

EHEC .47

4.5 Lipid A remodeling operons upregulated via activation of PhoPQ and

PmrAB .48

4.6 Induction of EHEC resistance to PMB acts through the iron-binding site

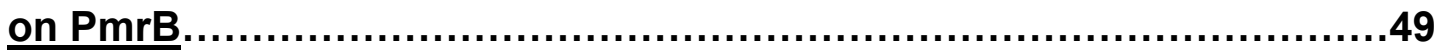

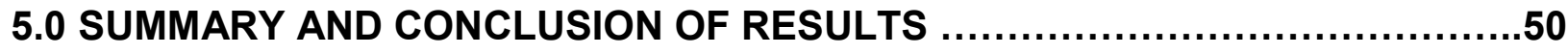

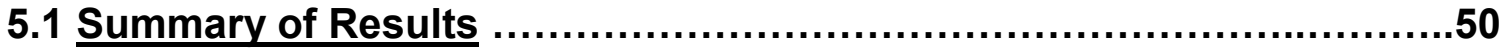

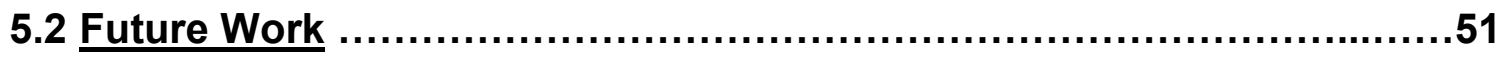

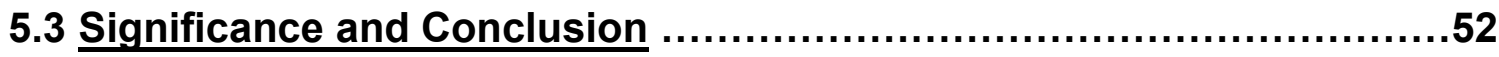

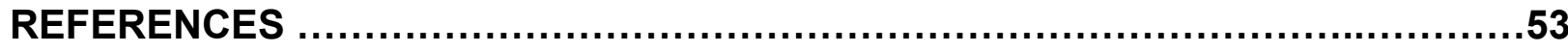


List of Tables

Table 1 Components of human bile.....................................................

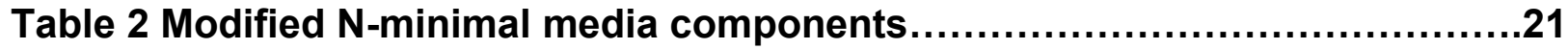

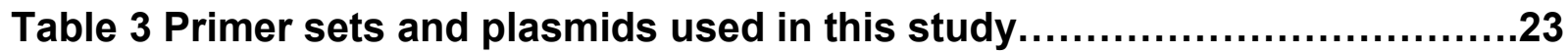

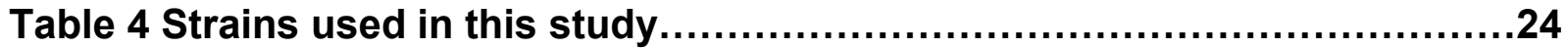

Table 5 EHEC survival under various physiological conditions.......................43 


\section{List of Figures}

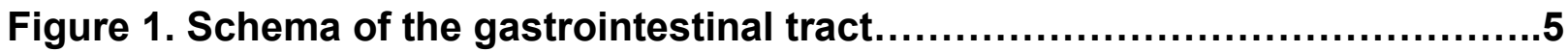

Figure 2. The activation of PhoPQ and PmrAB in Salmonella and E. coli............12

Figure 3. Low $\mathrm{pH}$ sensitizes to $\mathrm{Fe}^{3+}$ in a magnesium independent manner.........27

Figure 4. PMB killing concentrations of EHEC $86-24$ under various $\mathrm{Mg}^{2+}$ and $\mathrm{pH}$

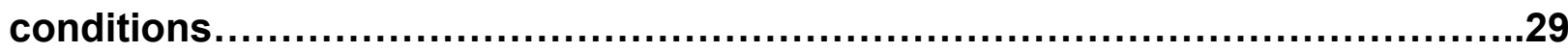

Figure 5A. Role of $p m r B$ gene in survival after PMB challenge.......................31

Figure 5B. Role of pmrA gene in survival after PMB challenge.......................33

Figure 6. PmrA plays a more critical role in PMB resistance .........................35

Figure 7. EHEC 86-24 Fe $\mathrm{Fe}^{3+} / \mathrm{BSM}$-induced resistance to PMB........................37

Figure 8. PmrAB modulation by ferric iron and bile salts in a PhoPQ dependent

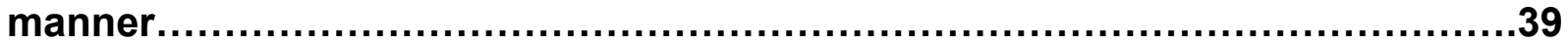

Figure 9. ArnBCADTEF promoter activity in a PmrAB dependent manner..........40

Figure 10. $\mathrm{Fe}^{3+} / \mathrm{BSM}$-induced resistance to PMB in the $\triangle p m r B E 36 A \ldots \ldots \ldots \ldots \ldots . . . . . .42$ 


\section{List of Abbreviations}

\begin{tabular}{ll}
\hline NAME & DISCREPTION \\
\hline Amp & Ampicillin resistance at a final concentration of $100 \mu \mathrm{g} / \mathrm{mL}$ \\
\hline Kan & Kanamycin resistant at $50 \mu \mathrm{g} / \mathrm{mL}$ \\
\hline ArnT & The enzyme that modifies lipid A with aminoarabinose \\
\hline PmrAB & Two-component signal transduction system (response and \\
& sensor regulator) \\
\hline bp & Base pairs \\
\hline BSM & Bile salt mix \\
\hline CAMPs & Cationic antimicrobial peptides \\
\hline CFU & Colony Forming Units \\
\hline DEC & Diarrheagenic Escherichia coli \\
\hline ER & Endoplasmic Reticulum \\
\hline EHEC & Enterohemorrhagic Escherichia coli \\
\hline HD-5 & Human defensin-5 \\
\hline HUS & Hemolytic uremic syndrome \\
\hline L-Ara4N & 4-amino-4-deoxy-L-arabinose \\
\hline LEE & Locus of Enterocyte Effacement \\
\hline LB & Lysogeny broth \\
\hline LPS & Lipopolysaccharide \\
\hline OD 600 & Optical density measured at a wavelength of $600 \mathrm{~nm}$ \\
\hline PBS & Phosphate buffered saline \\
\hline PCR & Polymerase Chain Reaction \\
\hline PMB & Polymyxin B \\
\hline rpm & Revolutions per minute \\
\hline Stx & Shiga-toxin \\
\hline Tir & Translocated intimin receptor \\
\hline T3SS & Type Ill secretion system \\
\hline wt & Wild-type \\
\hline & \\
\hline
\end{tabular}




\subsection{INTRODUCTION}

\subsection{Enterohemorrhagic Escherichia coli}

Escherichia coli are usually harmless to their hosts and tends to remain in confined areas within the gastrointestinal tract (GI) tract. However, over the years, some strains that were previously non-pathogenic have acquired virulence properties and cause infection in their hosts by compromising the epithelial barrier of the GI tract (Nataro \& Kaper, 1998). Enterohemorrhagic Escherichia coli (EHEC) serotype O157:H7 is a human pathogen that is the cause of severe bloody diarrhea and haemorrhagic uremic syndrome (HUS) worldwide (Nguyen and Sperandio, 2012). The mortality rate of patients that have been infected with EHEC is 3-17\% (Nguyen and Sperandio, 2012). Approximately $30 \%$ of individuals who survive this infection have permanent disabilities such as renal insufficiency, hypertension and loss of neurological function (Nguyen and Sperandio, 2012).

\subsection{Public Health Impact of EHEC}

Enterohemorrhagic E. coli (EHEC) was first acknowledged as a cause of human disease in 1982 following an outbreak in the United States of America. The illness was attributed to the consumption of undercooked hamburgers (Kaper et al., 2004). It was later documented that EHEC outbreaks are due to a wide variety of food items including sausages, lettuce, unpasteurized milk as well as public drinking water that has been contaminated with faecal samples from cattle and person-to-person transmission (Kaper et al., 2004; Kistemann et al., 2004). EHEC is particularly detrimental to public health as 
only a low infectious dose is required for infection (an appraised value of less than 100 bacterial cells) (Kaper et al., 2004). It has been found to infect children 5 years' old and younger as well as the elderly (Kistemann et al., 2004). Symptoms of infection include abdominal cramps, fever, vomiting and bloody diarrhoea or haemorrhagic colitis. The infection may even lead to a life-threatening disease referred to as hemolytic uremic syndrome (HUS) which is characterized by acute renal failure, and haemolytic anaemia (WHO, 2011). EHEC serotype O157:H7 is the most important pathogen in North America, the United Kingdom and Japan (Kaper et al., 2004). The pathogenic strain is so diverse in nature; twelve EHEC $0157: \mathrm{H} 7$ strains were isolated during a recent outbreak in a nursery school in Ehime Prefecture, Japan alone (Asano et al., 2013). There is also, currently no treatment for the prevention of EHEC infection as antibiotic treatment leads to the progression of HUS (Kistemann et al., 2004). It is thus important to assess EHEC virulence and the modulators of EHEC pathogenesis, in order to gain knowledge on various preventative strategies.

\subsection{Pathogenic Mechanisms of EHEC}

EHEC pathogenesis is characterized by $A / E$ lesions on the host's intestinal epithelial barrier (Kaper et al., 2004; Cleary et al., 2004). The ability to induce A/E lesions is due to locus of enterocyte effacement (LEE) pathogenicity island genes that encode virulence proteins that aid in bacterial adhesion and destruction of mammalian intestinal enterocytes (Bugarel et al., 2011). The LEE pathogenicity islands genes encode a type III secretion system (T3SS) which serves to secrete virulence proteins 
called effector proteins (Bugarel et al., 2011; Vallance \& Finlay, 2000). The T3SS acts like a needle that pierces the epithelial cell plasma membrane. The effector proteins are then injected into the cytoplasm of the host cell, where they then disrupt the cells' cytoskeletal and signalling machinery (Mueller et al., 2008). One particular effector protein, the translocated intimin receptor (Tir), is very important in the adhesion of EHEC to the host's intestinal epithelial cells. Once injected, Tir is integrated into the plasma membrane of the host's intestinal epithelial cells and then binds to the bacterial outer membrane adhesion protein, intimin. The interaction between Tir and intimin results in Tir clustering and results in the initiation of downstream signalling events within the host cell that leads to the formation of actin-rich pedestals (Wong et al., 2011).

The severity of EHEC infection is enhanced by the virulence factor, Shiga-toxin (Stx) (Kaper et al., 2004). There are two subgroups of Stx, Stx1 and Stx2, and their structures are very important for the pathogenesis of EHEC (Kaper et al., 2004); Stx contains five identical B subunits that form a homopentamer which serves to bind to the host intestinal epithelial cell and, a single A subunit that functions to cleave ribosomal RNA resulting in termination of protein synthesis (Bergan et al., 2012). EHEC releases Stx in the colon of warm-blooded mammals. It acts immediately on the endothethial cells of the colon, damaging them which results in symptoms such as bloody diarrhea, and haemorrhagic colitis (Kaper et al., 2004). Stx induces the depurination of an adenine residue on ribosomal RNA, disrupting protein synthesis in the host cell, thereby leading to the death of the cell (Lentz et al., 2011). 
Stx is also able to travel through the bloodstream to the kidney where it damages renal cells which can lead to hemolytic uremic syndrome (HUS) and potentially acute renal failure (Kaper et al., 2004). Cell death in the host serves as a signal for the activation of the coagulation cascade which leads to microthrombus formation, consumption of platelets and the fragmentation of red blood cells (Lentz et al., 2011). These are characteristics of HUS progression in the host (Lentz et al., 2011).

The stx genes are carried by lysogenic bacteriophages present within the EHEC strain (Wagner et al., 2001). A lysogenic bacteriophage is a viral bacterial infection in which the bacteriophage's nucleic acid sequence is integrated into the DNA genome sequence of the bacteria (Xu et al., 2012). Stx production is thus reliant on the phages life cycle (Wagner et al., 2001), which is triggered by the bacterial SOS response (Schüller, 2011). EHEC infection is thus hard to treat because Stx production is induced by DNA-damaging agents such as certain antibiotics; and more Stx production can lead to faster progression of the illness, HUS (Schüller, 2011).

\subsection{Role of host environmental stress on EHEC fitness \& infection ability}

EHEC colonizes the large intestines of mammals. As it passes along the GI tract, EHEC encounters a variety of stressors such as low $\mathrm{pH}$ in the stomach, and bile salts released in the small intestines (see Figure 1) (Aron-Wisnewsky et al., 2012). 


\section{Small intestine:}

- Duodenum

- Jejunum

Bile salts

pH 5.7-6.4

\section{Small intestine:}

- lleum

pH 7.3-7.7

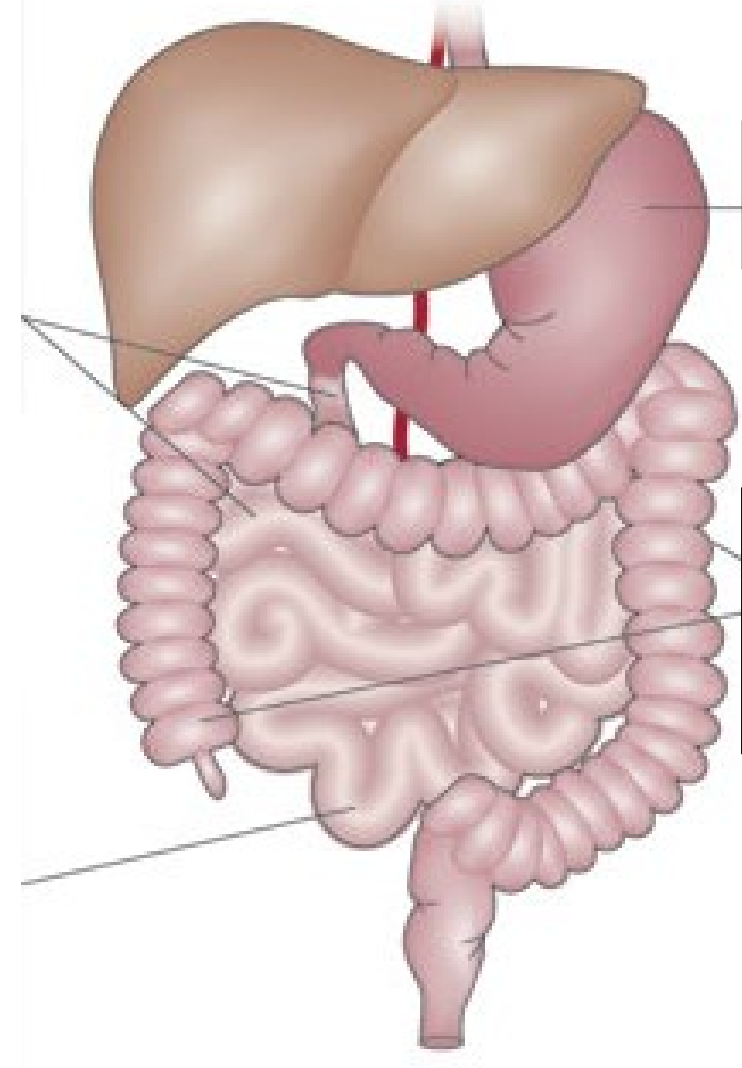

\section{Stomach}

$\mathrm{pH}$ 1-2
Large intestine

(EHEC colonization):

- Caecum

- Colon

pH 5.7-6.8

Figure 1. Schema of the gastrointestinal tract. EHEC encounter a variety of stresses when they pass through the GI tract before they colonize their target areas. Upon ingestion, they encounter stressors such as the low pH in the stomach and bile salts released from storage in the gall bladder into the small intestines. This is a modified image adapted from Aron-Wisnewsky et al (2012).

EHEC colonization of the human gastrointestinal (GI) tract largely depends on its ability to sense the external environment (Njoroge et al., 2012). In the GI tract of mammals, bacteria, pathogenic and non-pathogenic, encounter a variety of stressors that limit their survival, in some cases. Bacteria have developed a number of mechanisms that permit them to sense these environmental changes, and to adapt in ways that promote survival and virulence (Poole, 2012). The ability to sense these 
environmental stressors depends on the presence of two-component systems (TCS). These TCS are able to transduce a signal intracellularly, which results in the transcription of genes responsible for adaptive responses to environmental triggers (Weatherspoon-Griffin et al., 2014). Two-component systems are, therefore, a mechanism by which bacteria responds to a signalling cue, such as the presence of bile salts, in the environment, (Weatherspoon-Griffin et al., 2014), by producing effector resistance factors.

\subsection{Transition through the GI tract}

\subsubsection{The Composition and Function of Bile}

Bile is a complex organic fluid that is stored in the gall bladder and is released into the proximal small intestines, duodenum, upon consumption of a meal (Hofmann \& Eckmann, 2006). A major component of bile are bile salts and/or bile acids. Bile salts and/or bile acids are amphillic derivatives of steroids present in the body (Hofmann \& Eckmann, 2006). The majority of bile acids are composed of cholic acid conjugated to either glycine or taurine to form conjugate bile acids, glycoconjugates and tauroconjugates, respectively. This conjugation aids in their hydrophobic ability (Monte et al., 2009). Bile has many functions within the human body. It plays a function in the emulsification and solubilisation of fats as well as, to eliminate molecules such as cholesterol and other waste products from the body (Hofmann \& Eckmann, 2006). The Bile has also been found to be involved in the inhibition of growth of bacteria in the gastrointestinal tract. The antimicrobial effect of bile is accomplished through the disruption of membrane lipids which results in the cellular contents being expelled and 
consequently death of the bacterial cell (Begley et al., 2005). This is due to bile`s detergent-like properties which emulsifies and solubilizes the lipid bilayer of gut microbes (Hofmann \& Eckmann, 2006). The major components of bile include sodium, chloride and bile salts. The various components of bile are shown below in Table 1 (Begley et al., 2005).

\section{Table 1.}

Components of human bile.

\begin{tabular}{ll}
\hline Component & Concentrations \\
\hline Bile salts & $40 \mathrm{mmol} / \mathrm{L}$ \\
Sodium & $145 \mathrm{mmol} / \mathrm{L}$ \\
Chloride & $90 \mathrm{mmol} / \mathrm{L}$ \\
Cholesterol & $3 \mathrm{mmol} / \mathrm{L}$ \\
Potassium & $4 \mathrm{mmol} / \mathrm{L}$ \\
Phospholipids & $7 \mathrm{mmol} / \mathrm{L}$ \\
Bile acids & $3-45 \mathrm{~g} / \mathrm{L}$
\end{tabular}

The components of bile made in the liver and secreted into the duodenum via the bile duct. Components obtained from Begley et al (2005).

\subsubsection{Bile salts and Pathogenesis}

Bile exists in relatively high levels in the duodenum of the small intestines at physiological concentrations of 0.2 to $2 \%$ (Gunn, 2000). Bile salts, a component of bile, have been reported to significantly decrease the concentration of anaerobic organisms such as Bacteroides, Clostridia and Lactobacillus in the intestinal microflora (Binder et al., 1975). Other studies have shown, however, that bile enhances virulence properties and have thus aided in the adherence and colonization of pathogenic bacteria to 
epithelial cells (Kus et al., 2011). In a recent study, the exposure of EHEC to bile salts resulted in increased resistance to polymyxin $B(P M B)$, a cationic antimicrobial peptide. Microarray analysis showed that bile salts caused the upregulation of various genes in EHEC that contributed to this increased resistance (Kus et al., 2011).

Bile salts appear to provide some protective function for EHEC, resulting in the pathogenic strain acquiring various stress resistance strategies. In the presence of bile salts, a DNA microarray analysis has shown that genes in EHEC, encoding a twocomponent signal transduction system $(p m r A B)$ are upregulated, as are genes encoding the arn operon, genes encoding an efflux pump (acrAB) responsible for pumping bile outside the cell. It also revealed the down regulation of genes encoding a porin channel (OmpF), reducing the amount of bile that can enter the cell (Kus et al., 2011).

\subsubsection{Ferric Iron and Pathogenesis}

Iron is an essential element for both bacteria and their host. Mammals usually obtain their source of iron from an external source such as food or iron supplements and from old recycled red blood cells. Iron is thus found in two forms in the GI tract, free iron (ferrous iron and the majority as ferric iron) and bound to heme (Silva-Gomes et al., 2013). The solubility of ferric iron is higher in low $\mathrm{pH}$ conditions and is thus readily available for acquisition by iron-binding complexes in the GI tract (Messenger and Barclay, 1983). At high concentrations, however, iron can be toxic to cells by promoting the formation of oxidative radicals. High concentrations of iron in an oxygen-rich environment forms hydroxyl radicals from superoxide or hydrogen peroxide. These radicals can then target and disrupt macromolecules in the cell, such as proteins and 
carbohydrates, causing cell death (Kohgo et al., 2008). As a result, mammals regulate iron homeostasis and transport iron in the ferric form across the membrane of epithelial cells for storage in ferritin (Cherayil, 2011). Luminal iron not only promotes the pathogenicity and virulence of bacteria, but it also as an effect on host cell epithelial integrity (Kortman et al., 2012). Therefore, iron availability increases pathogenic potential of a number of pathogens. Upon bacterial infection, the host has devised a defense referred to as nutritional immunity where essential minerals, such as iron, are withheld or released at toxic levels to limit pathogenicity (Silva-Gomes et al., 2013). Some bacteria, however, have mechanisms to combat the host's immune defense. Borrelia burgdorferi, a pathogen that causes Lyme disease, evolved to substitute manganese in enzymes that require a divalent metal cation and therefore, does not require iron for growth (Skaar, 2010). Iron availability plays a vital role in pathogenicity and virulence of pathogenic bacteria in the GI tract (Messenger and Barclay, 1983). Consequently, EHEC needs to acquire ferric iron from their environments. They do this through the production of siderophores, phenolate complexes, that bind with high affinity to ferric iron and low affinity to ferrous iron (Messenger and Barclay, 1983). Iron influences many bacterial processes including growth and metabolism as well as the functioning of many proteins and enzymes required for colonization and survival (Messenger and Barclay, 1983). E. coli posses several iron transport systems, such as the ferric enterochelin system, that aid in its transport across the cell membrane (Messenger and Barclay, 1983).

Microbes work to develop strategies to adapt to the changing environment of the $\mathrm{GI}$ tract. These strategies include having cytoplasmic amino acid decarboxylase that serve 
to decarboxylate amino acids in order to neutralize protons that are in excess (Dahl et al., 2015), and the presence of efflux pumps that expel bactericidal components such as bile salts from the cytoplasm (Merritt and Donaldson, 2009). These stress resistant strategies can be credited to the presence of TCS, which are stimuli-response coupled regulatory systems (Koretke et al., 2000). These systems allow pathogenic microbes to sense the environment of the $\mathrm{Gl}$ tract.

\subsubsection{Host evasion strategies}

The two-component signal transduction system ( $p m r A B)$ is used by EHEC to sense environmental cues. The two-component system consists of a sensor and a response regulator domain that work together in order to sense and respond efficiently to environmental cues (Nixon et al., 1986). The sensor is located in the plasma membrane of the cell while the response regulator is located on the cytoplasmic side of the membrane, in order to transduce a signal downstream in response to signal received from the sensor (Nixon et al., 1986). In EHEC, pmrAB promoter shows a dose dependent response to BSM treatment (Kus et al., 2011).

In addition to sensing and responding to environmental cues in the environment, EHEC has a gene encoding a porin channel, OmpF, in the outer membrane of the lipid bilayer. The OmpF channel is thought to allow bile salts to enter the periplasm of the bacterial cell. Through microarray analysis, EHEC was observed to downregulate genes encoding OmpF in the presence of bile salts (Kus et al., 2011). A decrease in the channel expression may serve to limit the amount of bile that can enter the cell. Another gene that is involved in controlling bile entrance into the bacterial cell is an efflux pump 
$(a c r A B)$. The efflux pump is involved in expelling bile that has entered the cell (Hofmann \& Eckmann, 2006). EHEC has been shown to upregulate the genes encoding this efflux pump in the presence of bile salts (Kus et al., 2011), as a protective effect to prevent the disruption of lipid bilayers that compartmentalize the cell (Hofmann \& Eckmann, 2006).

The arn operon (arnBCADTEF and ugd) consists of genes encoding enzymes involved in the modification of lipid A on the LPS of pathogenic bacteria (Kus et al., 2011). Enzymes produced by these genes synthesize and transfer 4-amino-4-deoxy-Larabinose (L-Ara4N), a cationic sugar, to lipid A (Raetz, et al., 2007). EHEC contains the arn operon, arnBCADTEF, and in the presence of bile, its transcription is upregulated. L-Ara4N is positively charged at physiologically relevant $\mathrm{pH} 7$; therefore, the addition of L-Ara4N to the lipid A decreases the overall negative charge of the lipid A phosphate group. Hence, the overall charge of the bacterial membrane is decreased (Raetz et al., 2007). A decrease in the negative charge on the bacterial membrane thus makes it difficult for cationic antimicrobial peptides to bind and disrupt of the lipid bilayer of the bacteria to prevent pathogenic bacteria from colonizing (Yan et al., 2007).

Many pathogens have devised ways of amplifying their response to environmental stressors by forming networks with other TCSs. In E. coli, it has been shown that PhoPQ is also involved in the modulation of lipid A modification (Ruben et al., 2015). PhoQ and PmrB are the sensor histidine kinases that respond to different environmental cues (Ruben et al., 2015). PhoQ is a sensor of extracellular $\mathrm{Mg}^{2+}, \mathrm{Ca}^{2+}$ (Monsieurs et al., 2005), low $\mathrm{pH}$, as well as CAMPs, and activates the response regulator, PhoP (Ruben et al., 2015). The PhoPQ regulatory system's major function is to allow microbes to adapt to limiting $\mathrm{Mg}^{2+}$ conditions. Magnesium serves many 
functions in bacterial cells as its needed for the functioning of many enzymes as wells as the maintenance of the bacterial cell membrane (Lusk et al., 1968). Limiting $\mathrm{Mg}^{2+}$ conditions has been shown to lead to resistance to CAMPs in Pseudomonas aeruginosa (Macfarlene et al., 200). In Salmonella typhimurium, the importance of PhoPQ influence on virulence ability has been shown in a mutant strain (Monsieurs et al., 2005); microbes become sensitive to CAMPs in a phoPQ mutant (Groisman et al., 1992). One of the pathways that are controlled by PhoPQ activation leads to the transcription of a signal transduction protein referred to as PmrD. PmrD forms a communication bridge between PhoPQ and PmrAB (Figure 2). This protein functions to stabilize activated PmrA after phosphorylation by its sensor kinase, PmrB (Gunn and Miller, 1996).

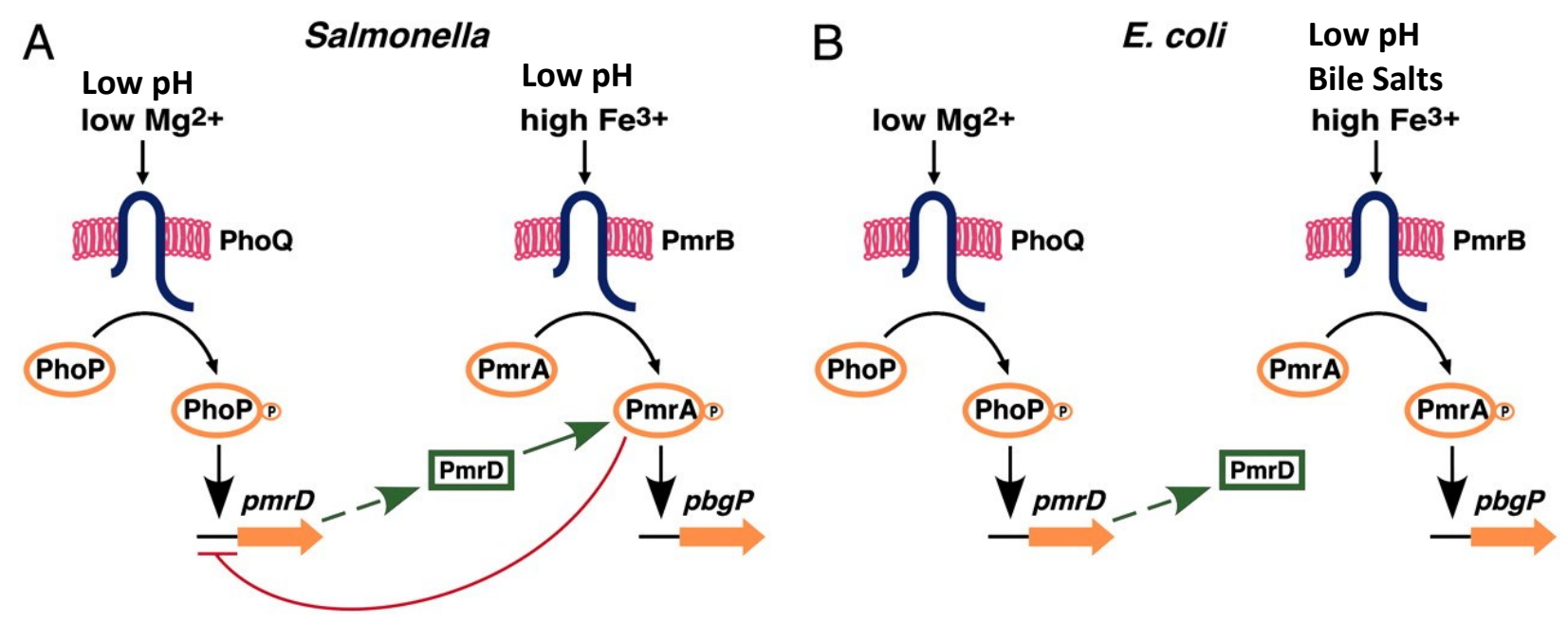

Figure 2. The activation of PhoPQ and PmrAB in Salmonella and E. Coli In Salmonella and E. coli, PhoPQ and PmrAB work together to promote the transcription of virulent genes. The transcription of PmrA-activated genes are dependent on low $\mathrm{Mg}^{2+}$ recognition by PhoPQ, the signal transduction protein (PmrD), and $\mathrm{Fe}^{3+}$ activation of PmrB (Winfield and Groisman, 2004). It was thought previously that pmrD in E. coli was non-functional (Groisman et al., 1992). However, Ruben et al. (2015) have demonstrated that PhoPQ and PmrAB are connected via pmrD. 
PmrB is regulated through its own external signal which has been show to include includes bile salts in EHEC 86-24 (Kus et al., 2011), and acidic pH and iron in the plant pathogen, Erwinia carotovora (Hyytiäinen et al., 2003). It was originally thought that PmrAB and PhoPQ were not connected in E. coli (Groisman et al., 1992). Recent studies have shown that they are connected in a PhoPQ-PmrD-dependent manner (Ruben et al., 2015). More interestingly, it was discovered that PmrD is still transcribed in a phoPQ mutant in $E$. coli $\mathrm{K}-12$ strain, and therefore, suggests that transcription of pmrD can occur independently of PhoPQ through an unknown mechanism (Ruben et al., 2015). The end goal of pathogens, however, remains the same. Pathogens need to survive and get to their area of colonization in the host. In the event that an external stressor is sensed, a response results in more resistance to possible stressors, the latter which could retard proliferation and growth. The PhoPQ-PmrAB system and the transcription of resistance genes such as $p b g P$ (also referred to as the arn operon) aids in survivability by modifying lipid A on the lipopolysaccharide in the bacterial membrane, resulting in resistance to bactericidal components that might be present in the host (Cheng et al., 2010).

\subsection{Cationic Antimicrobial Peptides}

\subsubsection{The role of CAMPs}

Antimicrobial peptides function as a part of the innate immune system in mammals, and they serve to protect against pathogenic microbes such as bacteria, viruses and fungi. Cationic antimicrobial peptides (CAMPs) are believed to kill bacterial cells by disrupting the membranes through electrostatic bound formations (Izadpanah \& 
Gallo, 2005). The selectivity of CAMPs against microbial entities has driven

development of clinical CAMPs, such as Polymyxin B, for in vitro studies. They function similarly to human CAMPs due to them having similar structures, and are effective in killing bacteria within minutes (Bradshaw, 2003).

Humans have three groups of CAMPs present in the body, defensins, histatins, and cathelicidins (Smet \& Contreras, 2005) and they exert their function on a broad spectrum of microbes (Hancock \& Diamond, 2000). There are two classes of defensins present within the human body, $\alpha$ helix-defensins and $\beta$ sheet-defensins. The $\alpha-$ defensins are generally produced and secreted by neutrophils and Paneth cells in the small intestines, whereas, $\beta$-defensins are produced and secreted by both leukocytes and epithelial cells (Schneider et al., 2005). Histatins are present in human saliva. They have two conformations depending on whether or not they are in aqueous or nonaqueous solution, random coil or $\alpha$-helices, respectively (Smet \& Contreras, 2005). Humans posses only one cathelicidin, LL-37, which forms a-helices in hydrophobic conditions (Smet \& Contreras, 2005).

\subsubsection{EHEC resistance to Cationic Antimicrobial Peptides}

Studies have shown that the modification of lipid A with L-Ara4N in bacteria such as Pseudomonas and Salmonella increases their resistance to CAMPs and PMB (Moskowitz et al., 2004; Trent et al., 2001; Raetz et al., 2007). One study has shown that exposure of EHEC to bile salt treatment results in the upregulation of genes associated with lipid A modifications and increased resistance to the cationic 
antimicrobial protein, polymyxin B (Kus et al., 2011). This was the first study to indicate a role for bile salts in cueing a pathogen to increase resistance to CAMPS.

Polymyxin $B(P M B)$, however, is not native to humans and EHEC, therefore, does not encounter it during its journey through the GI tract. Rather it is derived from a bacterium called Bacillus polymyxa and is often prescribed as an antibiotic to patients with gram-negative infections such as meningitis and sepsis (Cavaillon, 2011). PMB is an inexpensive, antimicrobial peptide that is most effective in killing or inhibiting the growth of most gram-negative bacteria (Duff \& Atkins, 1982). Since, EHEC, a gramnegative bacterium, has shown to upregulate genes that are involved in the modification of lipid A with L-Ara4N when exposed to bile salts (Kus et al., 2011), PMB is a good antimicrobial peptide model to test its resistance. The modified lipid A results in a less negative overall charge on the bacterial membrane, reducing the probability of PMB binding and disrupting the electrostatic interactions of the LPS.

Pathogens have to evade human CAMPs, such as human defensins, in order to get to their area of colonization. Human defensin-5 (HD-5) is an a-defensin that is more prevalent in the small intestinal lumen (Zhang et al., 2013) than in the rest of the GI tract. In the small intestine, HD-5 is found in concentrations between 1-5 $\mu \mathrm{M}$ and in the large intestines, less than $1 \mu \mathrm{M}$ (Thomassin et al., 2013). It is made and released from Paneth cells in the stomach (Ouellette, 2011). EHEC only encounters HD-5 transiently, where it then moves along the GI tract to colonize large intestines. Recent studies have now indicated that bile salt treated EHEC are more resistant to HD-5 that untreated EHEC (Gadishaw- Lue et al., 2015), suggesting then that the exposure to bile salts during passage through the $\mathrm{GI}$ tract have a physiological role in cueing the pathogen to 
upregulate resistance mechanisms to the CAMP encountered in this same locale. It is therefore clear that EHEC is capable of recognizing external stimuli, such as bile salts and ferric iron, and can activate effector proteins responsible for resistance against host defenses.

\subsection{Overall}

Extensive research has mostly been done on the characterization, structure and functionality of PmrAB in Salmonella, however, novel findings are emerging in E. coli. PmrAB has been reported to respond to ferric iron, and a $\mathrm{pH}$ range of 5.5-7.7 that results in an increase in virulence potential by inducing resistance to PMB (Cheng et al., 2010). In EHEC, research has also shown BasRS/PmrAB to respond to bile salts resulting in the transcription of the arn operon (arnBCADTEF) and ugd, genes responsible for the addition of L-Ara4N to the lipid A moiety of pathogenic bacteria (Kus et al., 2011). These findings suggest that pathogens have evolved in ways that allows them to sense the stressful environment of their host. It is thus important to understand these mechanisms as a means of possibly preventing bacterial infections.

\subsection{Research Rationale}

A physiologically relevant mix of bile salts has been shown to upregulate the transcription of PmrAB in EHEC 0157:H7 str. 86-24 (Kus et al., 2011). It also has been shown to enhance the expression of the arn operon that is involved in the modification of Lipid A on the lipopolysachharide of the outer membrane of the bacteria. This modification results in increased resistance to cationic antimicrobial peptides, such as PMB (Kus et al., 2011). The bile salt-induced increase in PMB resistance is $p m r B$ and 
arnT-dependent (Kus et al., 2011). This was the first report of a pmrB-dependent response to bile salts.

It has also been reported that PmrAB responds to various extracellular signals, one of which is ferric iron, in other strains like Salmonella enterica (Wösten et al., 2000). PmrB directly senses ferric iron and induces intracellular signalling that results in increased bacterial resistance to PMB (Fu et al., 2007).

An investigation of bile salt- and ferric iron- induced resistance in EHEC to CAMPs, PMB, will be undertaken to examine the role of PmrAB in bile salt- and ferric iron-induced resistance to CAMPs. The combinatory effect of bile and iron will be assessed to determine if there is a synergistic response to the combination that leads to CAMP resistance. Finally, it is important to understand how iron and bile salts mediate this enhanced CAMP resistance through a single TCS, PmrAB and whether these effects are mediated through the same sites or different sites on the PmrB sensor.

\subsection{Hypotheses \& Objectives}

1) It is hypothesized treatment with either a bile salt mixture or ferric iron induces BasRS-mediated EHEC resistance to CAMPs (PMB). Objectives:

- To assess resistance of wild type and pmrA and $p m r B$ mutants resistance to PMB before and after treatment with physiologically relevant bile salt mixtures.

- To assess resistance of wild type and pmrA and pmrB mutants to PMB before and after treatment with varying concentrations of ferric iron. 
2) It is hypothesized that the combinatory effect of bile salts and ferric iron generates an additive increase in PmrAB-mediated resistance to CAMPs (PMB).

Objectives:

- To assess resistance of wild type to PMB before and after treatment with a combination of BSM and iron.

3) It is hypothesized that bile salts interacts with a site on PmrB that is distinct from the iron-binding site of PmrB.

- To construct a site-directed mutant on the iron binding site of pmrB.

- To evaluate BSM or ferric iron or BSM and ferric iron induced resistance of wild type and the iron-binding site directed mutant to PMB. 


\section{MATERIALS AND METHODS}

\subsection{Killing Concentration Assay}

Microbroth dilution will be used to evaluate the antimicrobial activity of Polymyxin B (PMB). Deferoxamine mesylate, ferric iron chelator, was added to treatments that were exposed to ferric iron. It is added in both overnight and subculture in order to sequester all ferric iron present in solution, preventing possible pre-stimulatory effects. Isolated colonies of EHEC strain 86-24 were inoculated into modified N-minimal media (see Table 2) and grown overnight at $37^{\circ} \mathrm{C}$, static incubation. Subcultures of overnight samples were then prepared in $50 \mathrm{~mL}$ Erlenmeyer flasks in modified $\mathrm{N}$-minimal media (see Table 2), starting at an optical density of 0.05 measure at a wavelength of $600 \mathrm{~nm}$ using a BioPhotometer (Eppendorf) Spectrometer. Flasks were then placed in a $37^{\circ} \mathrm{C}$, $5 \% \mathrm{CO}_{2}$ incubator under static conditions to allow bacterial cells to grow to mid-log phase $\left(\mathrm{OD}_{600} \cong 0.5-0.8\right)$ for $3-4$ hours. Cells were then spun down at $3500 \mathrm{rpm}$ for 10 minutes and then washed with phosphate buffered saline (PBS) pH 7.4. Bacterial cells were then resuspended in $10 \mathrm{~mL}$ of modified $\mathrm{N}$-minimal media (see Table 2) and the $\mathrm{OD}_{600}$ of each sample was measured. The bacterial suspensions were then adjusted to $1 \times 10^{8} \mathrm{CFU} / \mathrm{mL}$ in $15 \mathrm{~mL}$ falcon tubes containing modified $\mathrm{N}$-minimal media (see Table 2). A 1/100 dilution was then carried out for each sample in $2 \mathrm{~mL}$ tubes, bringing the bacterial suspension to $5 \times 10^{6} \mathrm{CFU} / \mathrm{mL}$. After this, $50 \mu \mathrm{L}$ of each sample was then placed in a 96-well microtiter plate to test varying concentrations of PMB. $50 \mu \mathrm{L}$ of each PMB concentration was also placed into the microtiter plate. Serial dilutions were then carried out to determine the killing concentration of PMB for EHEC 86-24 after 60 
minutes. Colony counts were assessed the next day after overnight incubation of LB agar plates.

In order to determine the killing concentrations of ferric iron, a similar procedure was followed excluding the addition of deferoxamine mesylate. Varying concentrations of ferric iron were tested to determine the minimum inhibitory concentration for EHEC 86-24 after 60 minutes. The concentration below the minimum inhibitory concentration was then used to carry out killing assays.

\subsection{Resistance Assays}

Bile salts and Iron induced resistance to PMB

The experiment followed the same steps as outlined in Section 2.1 with the following additions. Bile salts pre-treatment was done during overnight and sub-culture. Isolated colonies of each strain were inoculated overnight in modified $\mathrm{N}$-minimal media (see Table 2) or modified N-minimal media (see Table 2) $+1.5 \%$ BSM and grown at

$37^{\circ} \mathrm{C}$, static incubation. For ferric iron pre-treatment, iron was introduced in the last hour of the subculture. 
Table 2.

Modified N-minimal media components

\begin{tabular}{|c|c|}
\hline Concentrations & Components \\
\hline $5 \mathrm{mM}$ & Potassium Chloride \\
\hline $7.5 \mathrm{mM}$ & Ammonium Sulphate \\
\hline $0.5 \mathrm{mM}$ & Potassium Sulphate \\
\hline $0.001 \mathrm{mM}$ & Potassium dihydrogen Phosphate \\
\hline $0.1 \mathrm{mM}$ & Tris-HCl pH 5.6 or $\mathrm{pH} 7.0$ \\
\hline $10 \mu \mathrm{M}$ or $10 \mathrm{mM}$ & Magnesium Chloride \\
\hline $38 \mathrm{mM}$ & Glycerol \\
\hline $0.1 \% \mathrm{w} / \mathrm{v}$ & Casamino acids \\
\hline $0.2 \% \mathrm{w} / \mathrm{v}$ & Glucose \\
\hline \multirow[t]{2}{*}{$0.75 \mathrm{~g} / \mathrm{L}$} & $\begin{array}{l}\text { Required amino acids (Arginine. } \mathrm{HCl} \text {, } \\
\text { Leucine, Lysine. } \mathrm{HCl} \text {, Glutamic acid } \\
\text { (monosodium salt), Histidine. } \mathrm{Hcl}\end{array}$ \\
\hline & Purines: Adenine and Uracil \\
\hline
\end{tabular}

\section{$2.3 \quad \beta$-Galactosidase reporter assay}

Promoters of genes, $p m r A B$ and arnBCADTEF, were cloned into the promoterless $\beta$-galactosidase expression vector pMC1403 (Kus et al., 2011). They were then transformed into both wild-type EHEC $86-24$ and $p m r B:: K^{r}{ }^{r}$ backgrounds (see Table 4 for constructs used). Bacteria were then cultured same as above, for both 
overnight and subculture. Activity was assessed using Sigma-Aldrich $\beta$-galactosidase reporter gene activity detection kit (Product Number Gal-A). Protocol followed was outlined by Sigma-Aldrich.

\section{$2.4 \quad$ Site-directed mutagenesis of pmrB}

PmrB fragment was amplified 500 bp upstream and downstream the mutation site $\left(36^{\text {th }}\right.$ position) (see Table 3 for primer sets). The pmrB fragment was then cloned into the pCR2.1 TOPO in the EcoRV site. Forward and reverse primers (see Table 3) containing a site mutation along with a silent cut site (see Table 3) was then used to amplify the pmrB fragment. The Quick-Change protocol was used in order to subclone the point mutated pmrB fragment into the suicide plasmid pRE112 $\left(\mathrm{Cm}^{\mathrm{R}}\right)$ using $\mathrm{Kpnl}$ and EcoRV restriction enzymes. pRE112 $\left(\mathrm{Cm}^{\mathrm{R}}\right)$ was then transformed into rubidium chloride chemically competent lambda pir strain (Sm10 $\lambda$ pir $-E$. coli), temperature sensitive strain $\left(30^{\circ} \mathrm{C}\right) . \mathrm{Sm} 10 \lambda$ pir (donor) and EHEC 86-24 (recipient) was then grown overnight at 30 and $37^{\circ} \mathrm{C}$, respectively. Donor and recipient were then mixed the next day in a microcentrifuge tube, cells were pelleted and resuspended in $100 \mu \mathrm{L}$ LB broth. Culture was then spot plated onto LB plates and left to mate for 16-18 hours. The next day colonies were re-streaked onto chloramphenicol plates. 
Table 3.

Primer sets and plasmids used in this study

Name Description

\section{Plasmids}

pCR2.1 Topo Used for the amplification of site mutation in pmrB (Shuman, 1991).

pRE112 Suicide plasmid used for transferal of $p m r B$ fragment as well as selectivity (Edwards et al., 1998).

\section{Primer sets}

Forward Primer

- used to amplify

pmrB fragment

Reverse Primer

- used to amplify

pmrB fragment

Forward

PmrBE36A

primer -

changes

glutamate $A A$ to an alanine (GAA

to GCA)

Reverse

PmrBE36A

primer
5'TCCCTGCAGGGATCGGTGCCGACGACTATCTGG 3'

- 500 bp upstream the area of interest on pmrB

5' CGGGGTACCCCGGGTCGAGCATGGTACTGAGTTCG 3'

- 500 bp downstream the area of interest on pmrB

AGCGTCTTCTGGCTATGGCATGCAAGTACTGAGCAGATTCAGCTG

- Scal R.E. silent site (ACC to ACU) - non-changing threonine AA

CAGCTGAATCTGCTCAGTACTTGCATGCCATAGCCAGAAGACGCT

- Reverse complement 
Table 4.

\section{Strains used in this study}

\begin{tabular}{|c|c|}
\hline Name & Description \\
\hline pMC1403 & $\begin{array}{l}\text { Plasmid was used to clone promoters with translation- } \\
\text { initiation sequences in order to asses their expression of } \\
\text { an active } \beta \text {-galactosidase fusion protein }\left(\mathrm{Amp}^{\mathrm{R}}\right) \\
\text { (Casadaban et al., 1980). }\end{array}$ \\
\hline pMC1403+PpmrA & $\begin{array}{l}\text { Promoter region of pmrAB cloned into EcoRl/BamHI sites of } \\
\qquad \text { MCS of pMC1403 (Amp }{ }^{R} \text { ) (Kus et al., 2011). }\end{array}$ \\
\hline pMC1403+ParnB & $\begin{array}{l}\text { Promoter region of } \operatorname{arnBCADTEF} \text { cloned into EcoRI/BamHI } \\
\text { sites of MCS of pMC1403 (Amp }{ }^{R} \text { (Kus et al., 2011). }\end{array}$ \\
\hline 86-24 & $\begin{array}{l}\text { Wild type EHEC 86-24 O157:H7 strain 86-24 obtained from } \\
\text { Dr. Jorge Giron, University of Florida (Griffin et al., } \\
\text { 1988). }\end{array}$ \\
\hline 86-24 pmrB::Kan ${ }^{R}$ & 86-24 with $\operatorname{Kan}^{\mathrm{R}}$ disruption of $p m r B\left(\operatorname{Kan}^{\mathrm{R}}\right)$ (Kus et al., 2011). \\
\hline 86-24 pmrA::Kan ${ }^{\mathrm{R}}$ & 86-24 with $\mathrm{Kan}^{\mathrm{R}}$ disruption of $p m r A\left(\operatorname{Kan}^{\mathrm{R}}\right)$ (Kus et al., 2011). \\
\hline 86-24 pMC1403 & $\begin{array}{l}\text { 86-24 transformed with } \mathrm{pMC1403} \text { was used as negative } \\
\text { control in } \beta \text {-galactosidase reporter assays }\left(\mathrm{Amp}^{\mathrm{R}}\right)\end{array}$ \\
\hline 86-24pmrB_PpmrA & $\begin{array}{l}\text { 86-24 pmrB::Kan }{ }^{R} \text { transformed with pMC1403+PpmrAB } \\
\qquad\left(\mathrm{Amp}^{\mathrm{R}}\right)(\text { Kus et al., 2011). }\end{array}$ \\
\hline 86-24pmrB_ParnB & 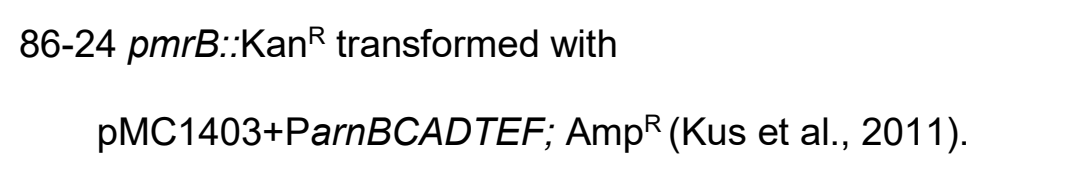 \\
\hline PmrBE36A & Site-directed mutant of the $36^{\text {th }}$ position on pmrB (This study) \\
\hline
\end{tabular}




\section{$2.5 \quad$ Statistical Analysis}

Results are presented as means \pm standard error of mean. Student $t$ tests used to assess the difference between control and bile salts \& ferric iron treatments. 


\section{RESULTS}

\subsection{Determination of Ferric Iron Toxicity level for EHEC}

Ferric Iron can be toxic at very high levels for bacteria as it produces oxygen radicals that can cause cell death (Cherayil, 2011). It is thus, important to find the concentration at which this occurs, so that subsequent experiments can be done below this particular concentration.

Recall that low magnesium and low $\mathrm{pH}$ are triggers for PhoPQ activation. Since, CAMP resistance is not only dependent on PmrAB activation but also PhoPQ activation, the media used was supplemented with different concentrations of magnesium at different $\mathrm{pH}$ values. $1-10 \mu \mathrm{M} \mathrm{Mg}^{2+}$ is considered low and 1-10 $\mathrm{mM}$ is considered high $\mathrm{Mg}^{2+}$. Killing assays showed that in modified $\mathrm{N}$-minimal media supplemented with low or high magnesium (10 $\mu \mathrm{M}$ or $10 \mathrm{mM} \mathrm{MgCl} 2)$ at acidic $\mathrm{pH}(\mathrm{pH} 5.8)$, the concentration that completely killed EHEC 86-24 was $8 \mu \mathrm{M} \mathrm{Fe}^{3+}$. In modified N-minimal media supplemented with low or high magnesium $(10 \mu \mathrm{M}$ or $10 \mathrm{mM} \mathrm{MgCl} 2)$ at neutral $\mathrm{pH}(\mathrm{pH}$ 7.0), the concentration that completely killed EHEC 86-24 was $32 \mu \mathrm{M} \mathrm{Fe}^{3+}$ (see Table 5). The ferric iron concentration used for the subsequent killing assays were 1 -fold below the determined killing concentrations shown in Table $\mathbf{5}$. 


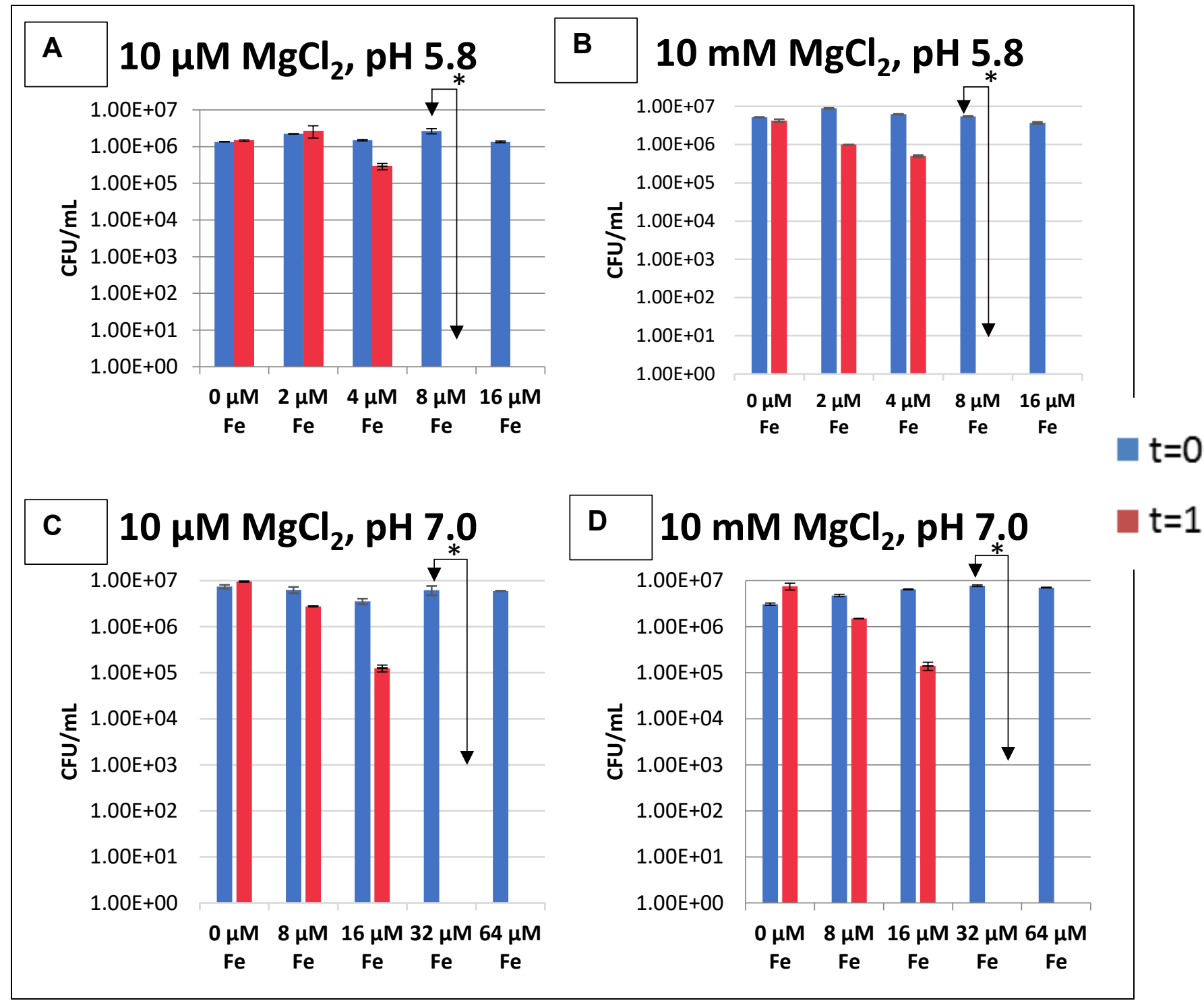

Figure 3. Low $\mathrm{pH}$ sensitizes to $\mathrm{Fe}^{3+}$ in a magnesium independent manner EHEC was grown overnight in Modified N-Minimal Media supplemented with a specific concentration of $\mathrm{Mg}^{2+}$ and $\mathrm{pH}$ (as shown above graphs) for 18 hours and then subcultured in the same media. Bacteria were then challenged with varying concentrations of Iron for 1 hour in a static incubator at $37^{\circ} \mathrm{C}$. Serial dilutions $\left(10^{1}-10^{3}\right.$ for $t=0$ and $10^{1}$ $10^{3}$ for $\mathrm{t}=1$ ) were carried and plated. Retrievable colony counts were assessed the next day after static incubation at $37^{\circ} \mathrm{C}$ for 11 hours. Determined from 3 biological sample, 2 technical replicates $\left({ }^{*} p<0.05\right)$. 


\subsection{Killing concentration of PMB for EHEC 86-24}

It's important to determine the concentration at which CAMPs inhibit the visible growth of pathogenic bacteria in order to confirm possible resistance by a substance/molecule. As a result, before determining bile salts-/ferric iron-induced resistance to PMB, a Killing Assay had to be carried out in order to determine the concentration that completely kills all bacteria after 1 hour. The results demonstrate the importance of magnesium and $\mathrm{pH}$ modulation of $\mathrm{PhoPQ}$ and $\mathrm{PmrAB}$ in resistance to PMB. Under low and high magnesium (10 $\mu \mathrm{M}$ and $10 \mathrm{mM})$ and low $\mathrm{pH}(5.8)$ conditions, the killing concentration for EHEC $86-24$ is $64 \mu \mathrm{g} / \mathrm{mL}$ and $32 \mu \mathrm{g} / \mathrm{mL}$ PMB, respectively. Under low and high magnesium (10 $\mu \mathrm{M}$ and $10 \mathrm{mM})$ and neutral $\mathrm{pH}(7.0)$ conditions, the killing concentration for EHEC $86-24$ is $8 \mu \mathrm{g} / \mathrm{mL}$ and $4 \mu \mathrm{g} / \mathrm{mL} P M B$, respectively. 

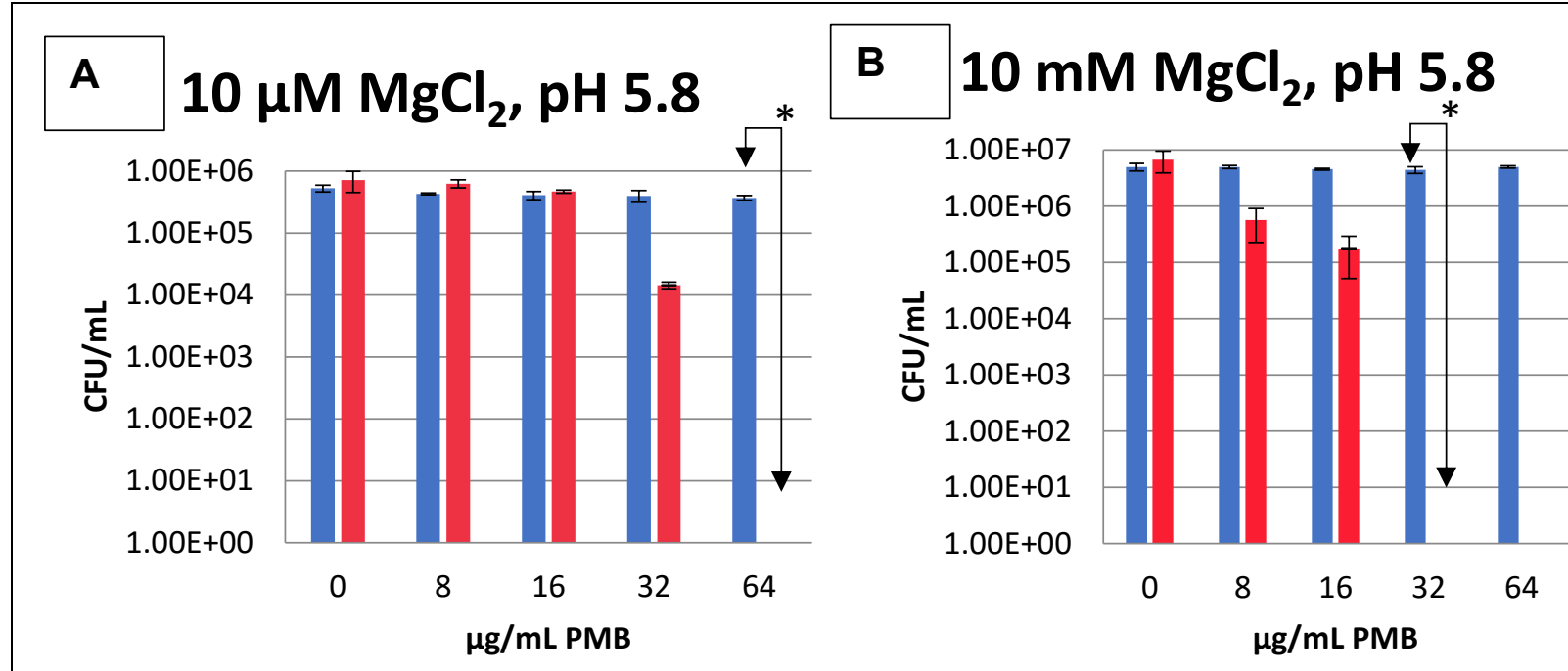

\section{C $\quad 10 \mu \mathrm{M} \mathrm{MgCl}_{2}, \mathrm{pH} 7.0$}

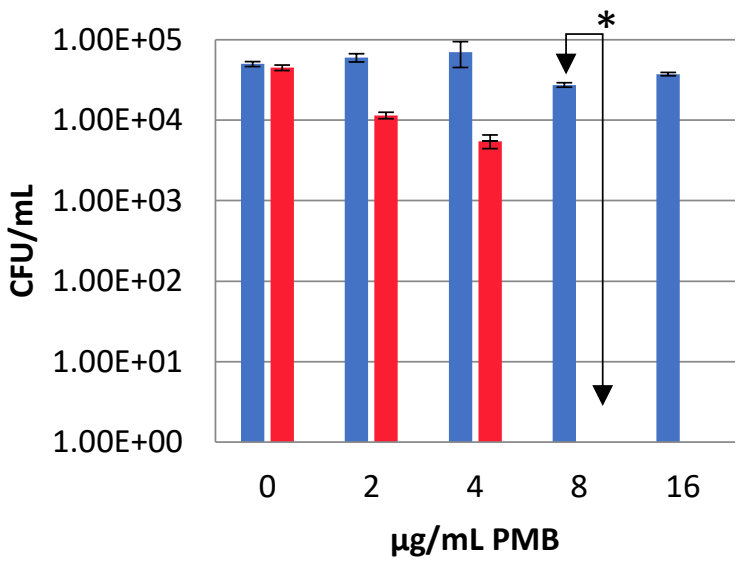

D $\quad 10 \mathrm{mM} \mathrm{MgCl}$, pH 7.0

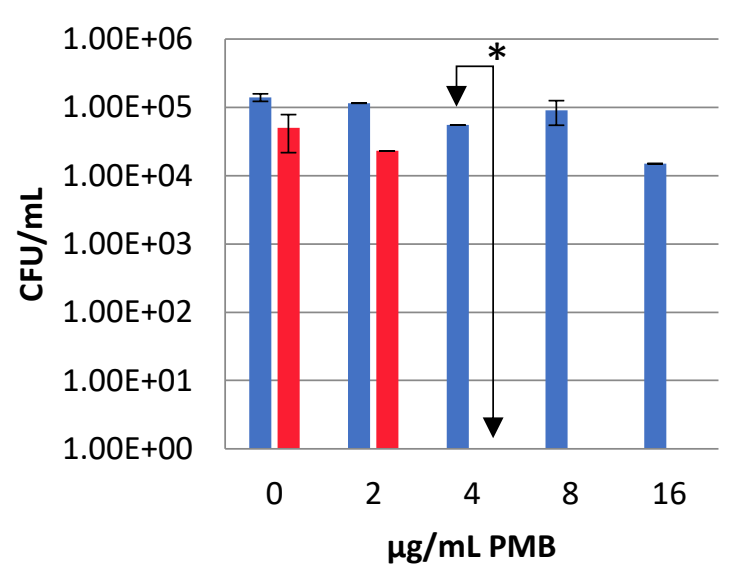

Figure 4. PMB killing concentrations of EHEC 86-24 under various $\mathbf{M g}^{2+}$ and $\mathbf{p H}$ conditions EHEC was grown overnight in Modified N-Minimal Media supplemented with a specific concentration and $\mathrm{pH}$ (as shown above graphs) for 12-16 hours and then sub-cultured in the same media. Bacteria was then challenged with varying concentrations of $\mathrm{PMB}$ for 1 hour in a static incubator at $37^{\circ} \mathrm{C}, 5 \% \mathrm{CO}_{2}$. Serial dilutions $\left(10^{1}-10^{3}\right.$ for $\mathrm{t}=0$ and $10^{1}-10^{3}$ for $\left.\mathrm{t}=1\right)$ were carried and plated. Retrievable colony counts were assessed the next day after static incubation at $37^{\circ} \mathrm{C}$ for 11 hours. Determined from 3 biological sample, 3 technical replicates $(p<0.0001)$. 


\subsection{Role of pmrA and pmrB in survival after PMB challenge}

The role of PmrB, the sensor kinase of the TCS, PmrAB, in EHEC survival after PMB challenge was evaluated using the isogenic mutant, $p m r B$, in a 1 hour killing assay. The killing PMB concentrations for wt were used to assess survivability. All four sets of conditions were tested. Results shown in Figure $5 \mathrm{~A}$ below indicate that $p m r B$ is critical for survival at any concentration of PMB and under any of the four sets of conditions tested. This suggests that regardless of the involvement of PhoPQ in promoting PMB resistance, $p m r B$ is critically required. 


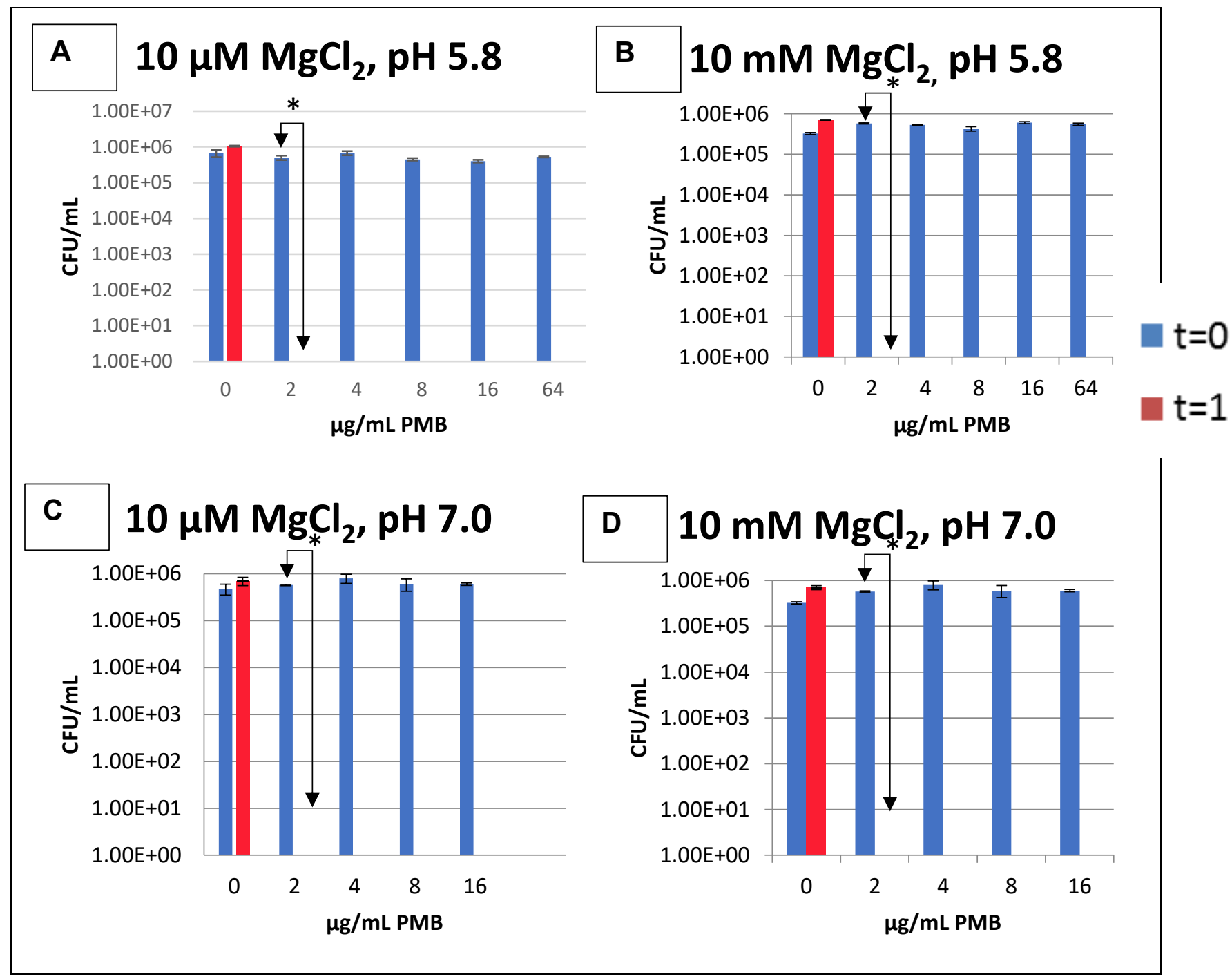

Figure 5A. Role of $p m r B$ gene in survival after PMB challenge $\triangle p m r B$ was grown overnight in $10 \mu \mathrm{M} / \mathrm{mM} \mathrm{MgCl}_{2}$, pH 5.8 and 7.0 with $300 \mu \mathrm{M}$ Deferoxamine mesylate for 12-16 hours and then sub-cultured in the same media. Bacteria were then challenged with varying concentrations of $\mathrm{PMB}$ for 1 hour in a static incubator at $37^{\circ} \mathrm{C}$. Serial dilutions $\left(10^{1}-10^{3}\right.$ for $t=0$ and $10^{1}-10^{3}$ for $\left.t=1\right)$ were carried and plated. Retrievable colony counts were assessed the next day after static incubation at $37^{\circ} \mathrm{C}$ for 11 hours. Determined from 2 biological sample, 3 technical replicates $\left({ }^{*} p<0.05\right)$. 
Similarly, the role of $p m r A$, the response regulator, in the survival after PMB challenge was also evaluated using a 1 hour killing assay. All four sets of conditions were tested. Results shown in Figure $5 \mathrm{~B}$ below indicate that $p m r A$ is also critical for survival at any concentration of PMB and under any of the four sets of conditions tested. This suggests that regardless of the involvement of PhoPQ in promoting PMB resistance, pmrA is critically required for EHEC survival. 


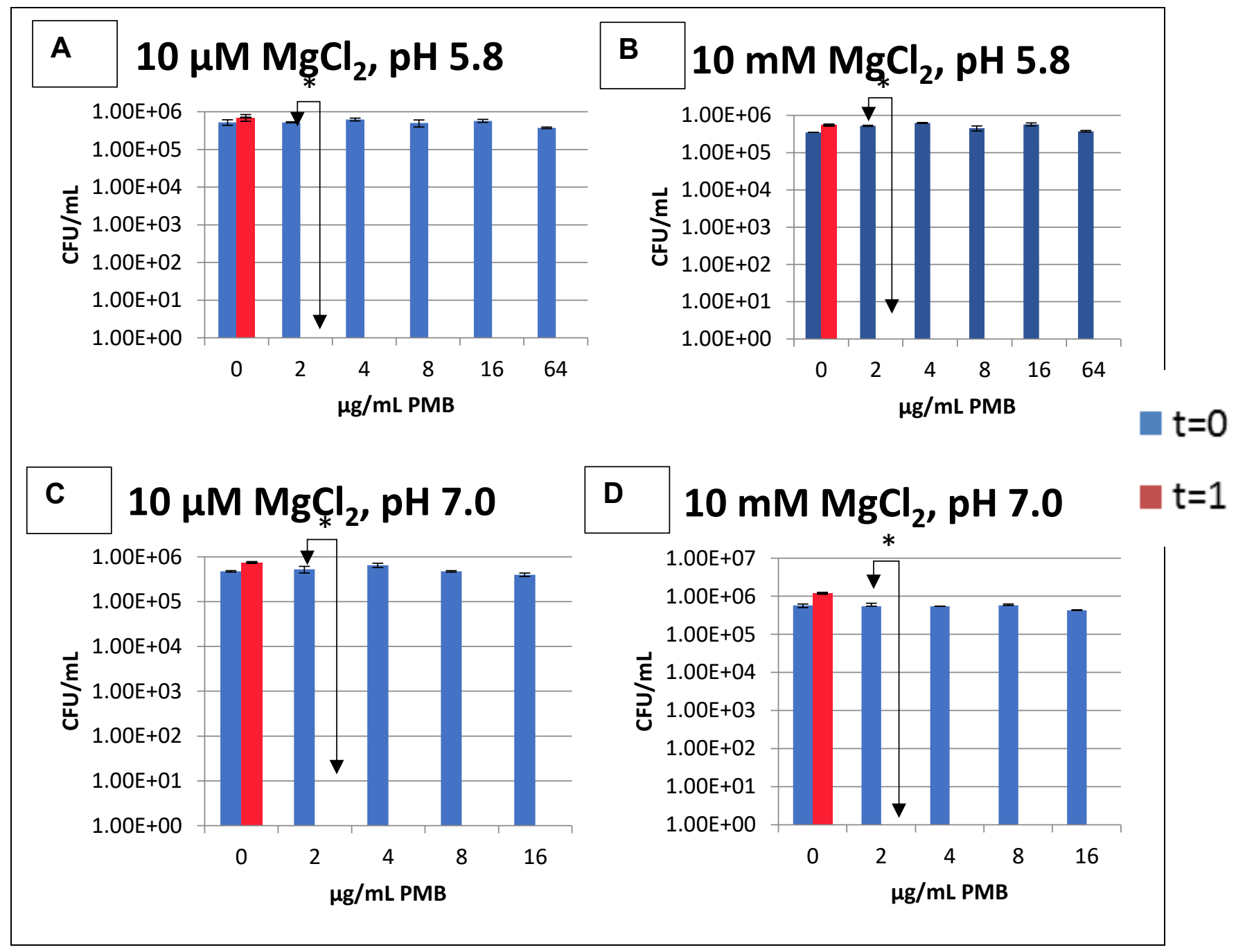

Figure 5B. Role of pmrA gene in survival after PMB challenge $\triangle p m r A$ was grown overnight in $10 \mu \mathrm{M} / \mathrm{mM} \mathrm{MgCl}_{2}$, pH 5.8 and 7.0 with $300 \mu \mathrm{M}$ Deferoxamine mesylate for 12-16 hours and then sub-cultured in the same media. Bacteria were then challenged with varying concentrations of PMB for 1 hour in a static incubator at $37^{\circ} \mathrm{C}$. Serial dilutions $\left(10^{1}-10^{3}\right.$ for $t=0$ and $10^{1}-10^{3}$ for $\left.t=1\right)$ were carried and plated. Retrievable colony counts were assessed the next day after static incubation, at $37^{\circ} \mathrm{C}$ for 11 hours. Determined from 2 biological sample, 3 technical replicates $\left({ }^{*} p<0.05\right)$. 


\subsubsection{The Relative Roles of pmrA and pmrB in PMB resistance}

To evaluate the relative importance of the $p m r A$ and $p m r B$ for PMB challenge, survival of each of the mutants was assessed across a sub inhibitory range of PMB concentrations. Results shown in Figure 6 below indicate that mutation of the pmrA resulted in killing at lower concentrations of $\mathrm{PMB}$ relative to the $p m r B$ mutation under 3 of the 4 sets of conditions. Only under conditions of high $\mathrm{Mg}^{+2}$ and neutral $\mathrm{pH}$, which are inducing for neither PhoPQ nor PmrAB, were the mutations in each of $p m r A$ and $p m r B$ equivalently important for survival to PMB challenge. These data suggest that $p m r A$, the response regulator, is relatively more important for the PMB challenge response as indicated by a significantly different phenotype at lower PMB concentrations. Once again, this confirms the central role of $p m r A$ and $p m r B$ to the induction of EHEC resistance to PMB. 


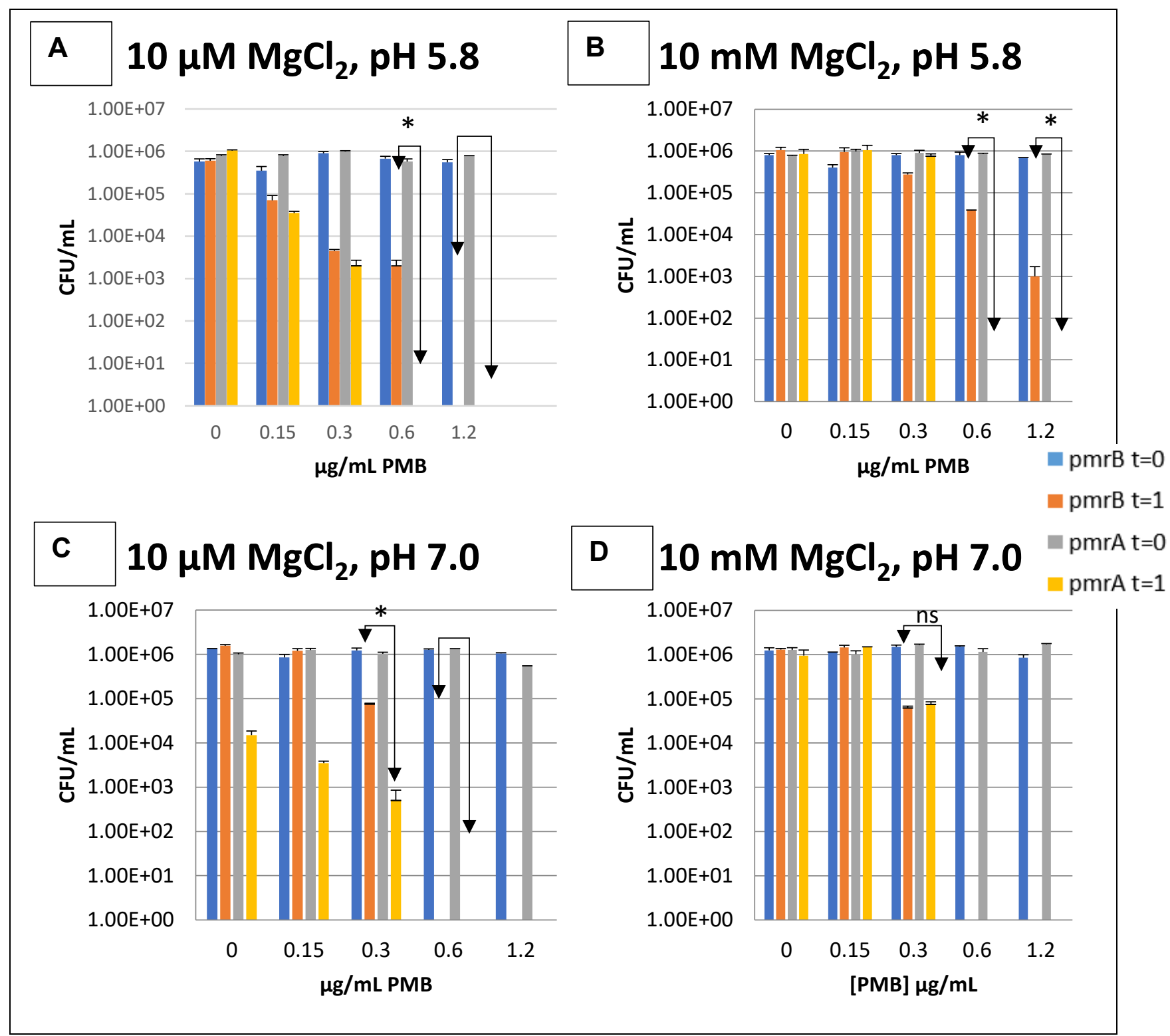

Figure 6. PmrA plays a more critical role in PMB resistance $\triangle p m r B \& \Delta p m r A$ was grown overnight in $10 \mu \mathrm{M} / \mathrm{mM} \mathrm{MgCl}_{2}, \mathrm{pH} 5.8$ and 7.0 with $300 \mu \mathrm{M}$ Deferoxamine mesylate for 12-16 hours and then sub-cultured in the same media. Bacteria were then challenged with varying concentrations of $\mathrm{PMB}$ for 1 hour in a static incubator at $37^{\circ} \mathrm{C}$. Serial dilutions $\left(10^{1}-10^{3}\right.$ for $t=0$ and $10^{1}-10^{3}$ for $\left.t=1\right)$ were carried and plated. Retrievable colony counts were assessed the next day after static incubation at $37^{\circ} \mathrm{C}$ for 11 hours. Determined from 2 biological sample, 3 technical replicates. $\left({ }^{*} p<0.05\right)$. 


\subsection{Bile salts- and Ferric Iron-induced resistance to PMB}

The induction of PMB resistance by each of ferric iron and bile salt mix was evaluated using a 1 hour killing assay. Results shown in Figure 7 below indicate that each of ferric iron and bile salt mix can induce resistance to PMB but only under conditions that included low $\mathrm{Mg}^{+2}$ levels. This implies that PhoPQ is required or at least involved in BSM and iron-induced resistance to PMB and that without the strong induction of PhoPQ by low $\mathrm{Mg}^{+2}$ levels, neither bile salt mix nor ferric are able to induce resistance to PMB. See Table 5 for the killing concentrations of PMB used under each magnesium and $\mathrm{pH}$ condition. Also, the concentration of ferric iron used in each condition was 1 -fold below the killing concentration (see Table 5 for ferric iron killing concentration under each condition). 


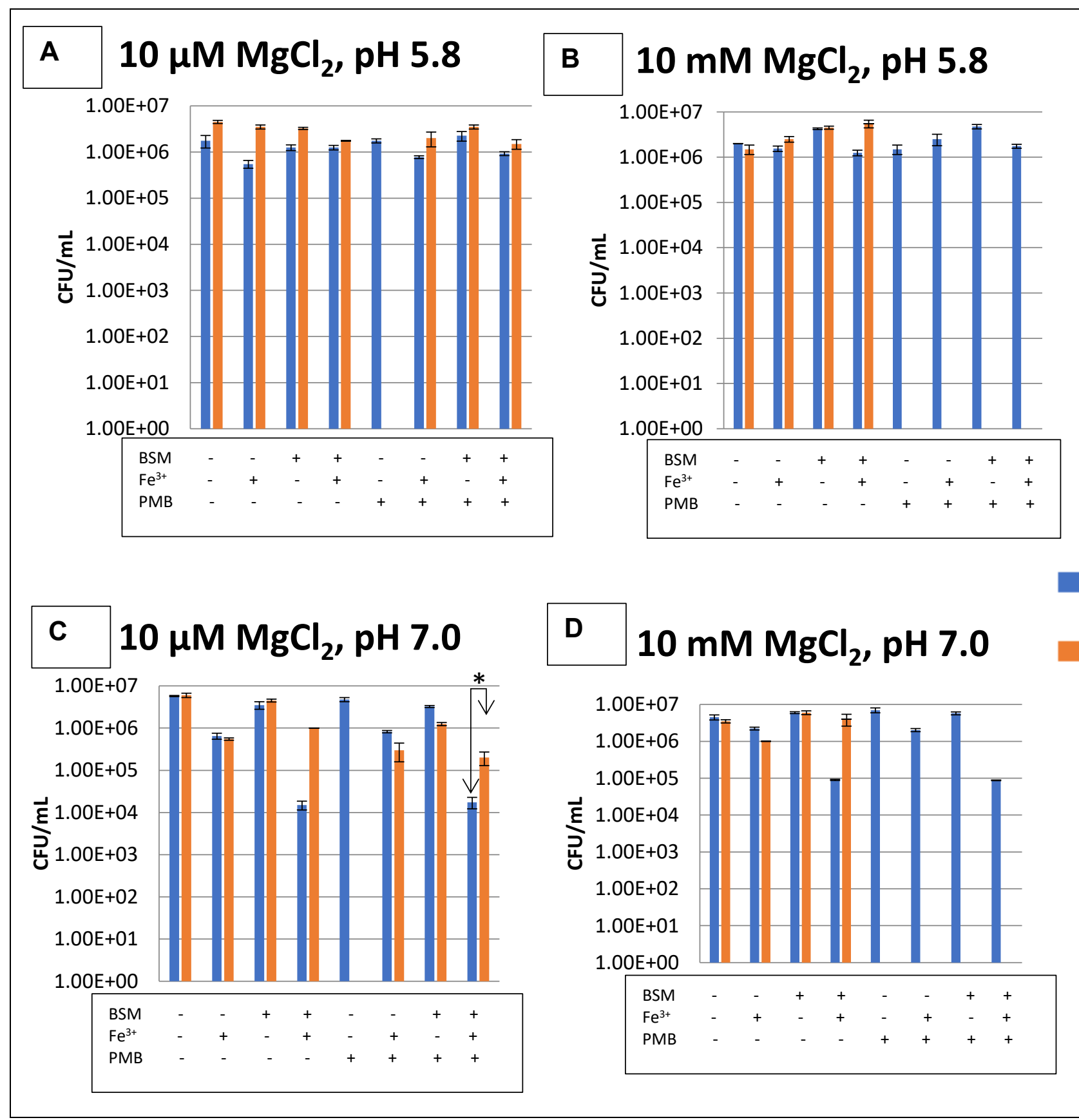

Figure 7. EHEC 86-24 Fe3+/BSM-induced resistance to PMB EHEC 86-24 was grown overnight in either $10 \mu \mathrm{M} / \mathrm{mM} \mathrm{MgCl}_{2}$, $\mathrm{pH} 5.8 \mathrm{or} \mathrm{pH} 7.0$ with/without $300 \mu \mathrm{M}$ Deferoxamine mesylate (+/- $1.5 \%$ BSM treatment) for 12-16 hours and then sub-cultured in the same media (+/- BSM treatment) for 4 hours, in the last hour Iron was added to specific conditions. Bacteria were then challenged with varying concentrations of $\mathrm{PMB}$ for 1 hour in a static incubator at $37^{\circ} \mathrm{C}$. Serial dilutions $\left(10^{1}-10^{3}\right.$ for $\mathrm{t}=0$ and $10^{1}-10^{3}$ for $\left.\mathrm{t}=1\right)$ were carried and plated. Retrievable colony counts were assessed the next day after static incubation at $37^{\circ} \mathrm{C}$ for 11 hours. Determined from 2 biological sample, 3 technical replicates $\left({ }^{*} p<0.05\right)$. 


\subsection{Promoter activity of pmrAB operon and arn BCADTEF in response to bile salts}

and ferric iron treatment

$\beta$-galactosidase reporter assays have been shown to demonstrate activity from EHEC promoters, pmrAB and arnBCADTEF, in wt 86-24. Enhanced responses were observed under increasing bile salt mixture conditions in DMEM (Kus et al., 2011). In this present study, under control magnesium and $\mathrm{pH}$ conditions, presumably modulating PhoPQ and PmrAB gene regulation, the activity of lipid $A$ remodeling operons were assessed. In figure 8, the promoter activity of $p m r A B$ after bile salts and ferric iron showed significant activity under all conditions except in the presence of high magnesium and neutral $\mathrm{pH}, \mathrm{pmr} \mathrm{AB}$ and $\mathrm{phoPQ}$ unresponsive conditions. This was also mirrored in figure 9, the promoter activity of arnBCADTEF. This implies that both PhoPQ and PmrAB are required for lipid A remodeling and consequently, PMB resistance. 

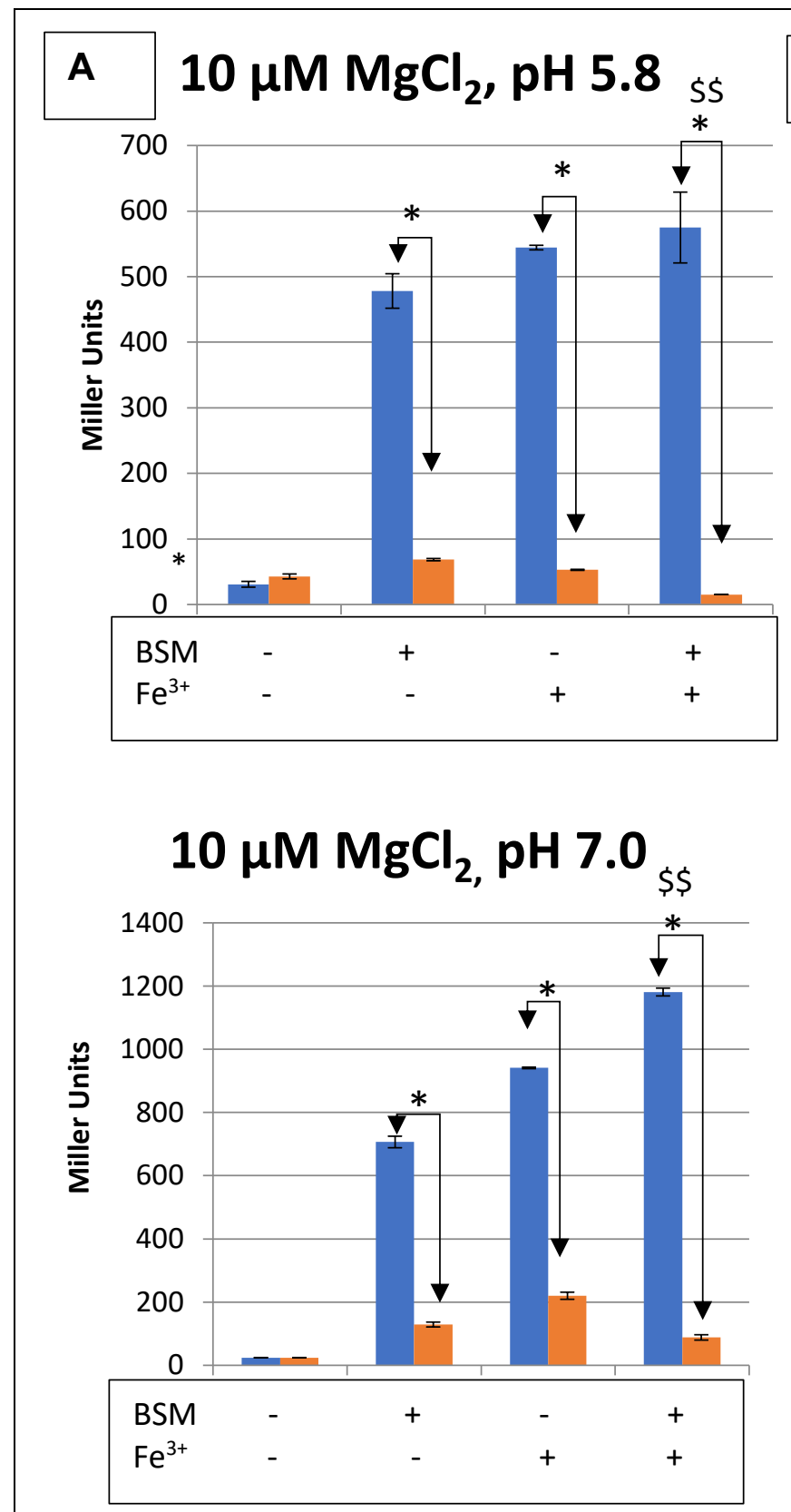

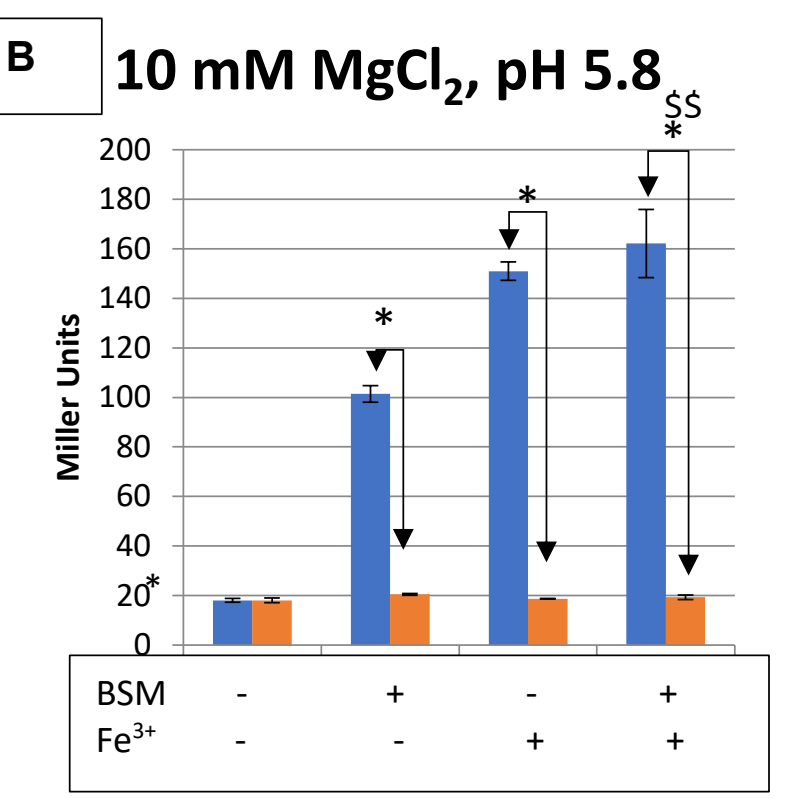

- WT

$10 \mathrm{mM} \mathrm{MgCl}, \mathrm{pH} 7.0=\mathrm{MT} p m r B:: \mathrm{Kan}^{r}$

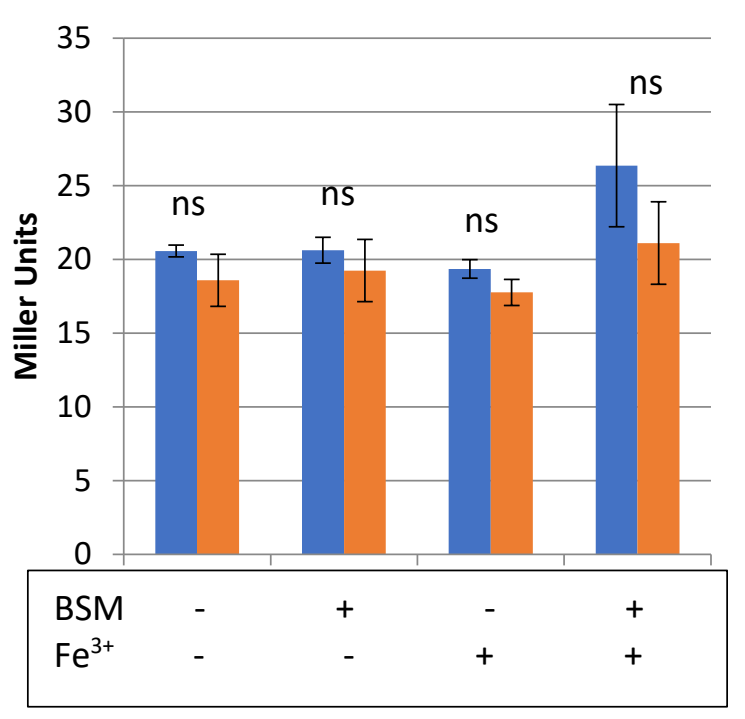

Figure 8. PmrAB modulation by ferric iron and bile salts in a PhoPQ dependent manner $\beta$-Galactosidase reporter assays demonstrate EHEC promoter activity after overnight and subculture in $10 \mu \mathrm{M} / \mathrm{mM} \mathrm{MgCl}_{2}$ at pH 5.8/7.0. The activity of the promoters for pmrAB were examined in $\beta$-galactosidase expression assays in both the wild-type (WT) 86-24 and $p m r B:: K^{r}{ }^{r}$. Bile salts and Iron treatment significantly different from other treatments in WT $(\$ \$)$. Data shown is for 3 biological replicates $\left({ }^{*} p<0.05\right)$. 


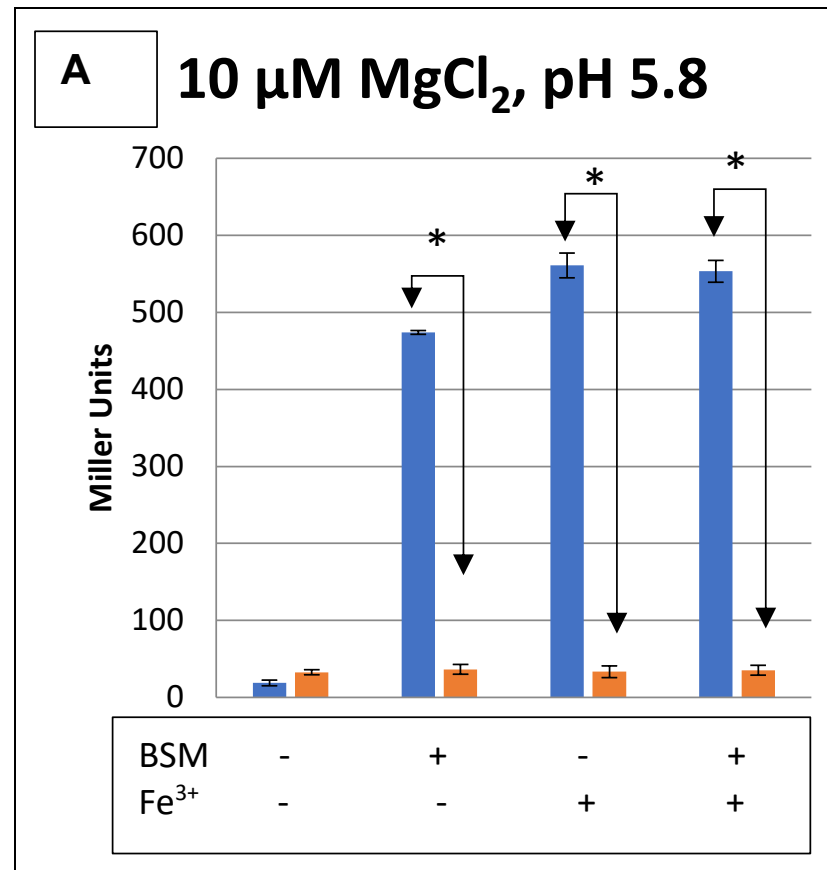

B $10 \mathrm{mM} \mathrm{MgCl}, \mathrm{pH} 5.8$
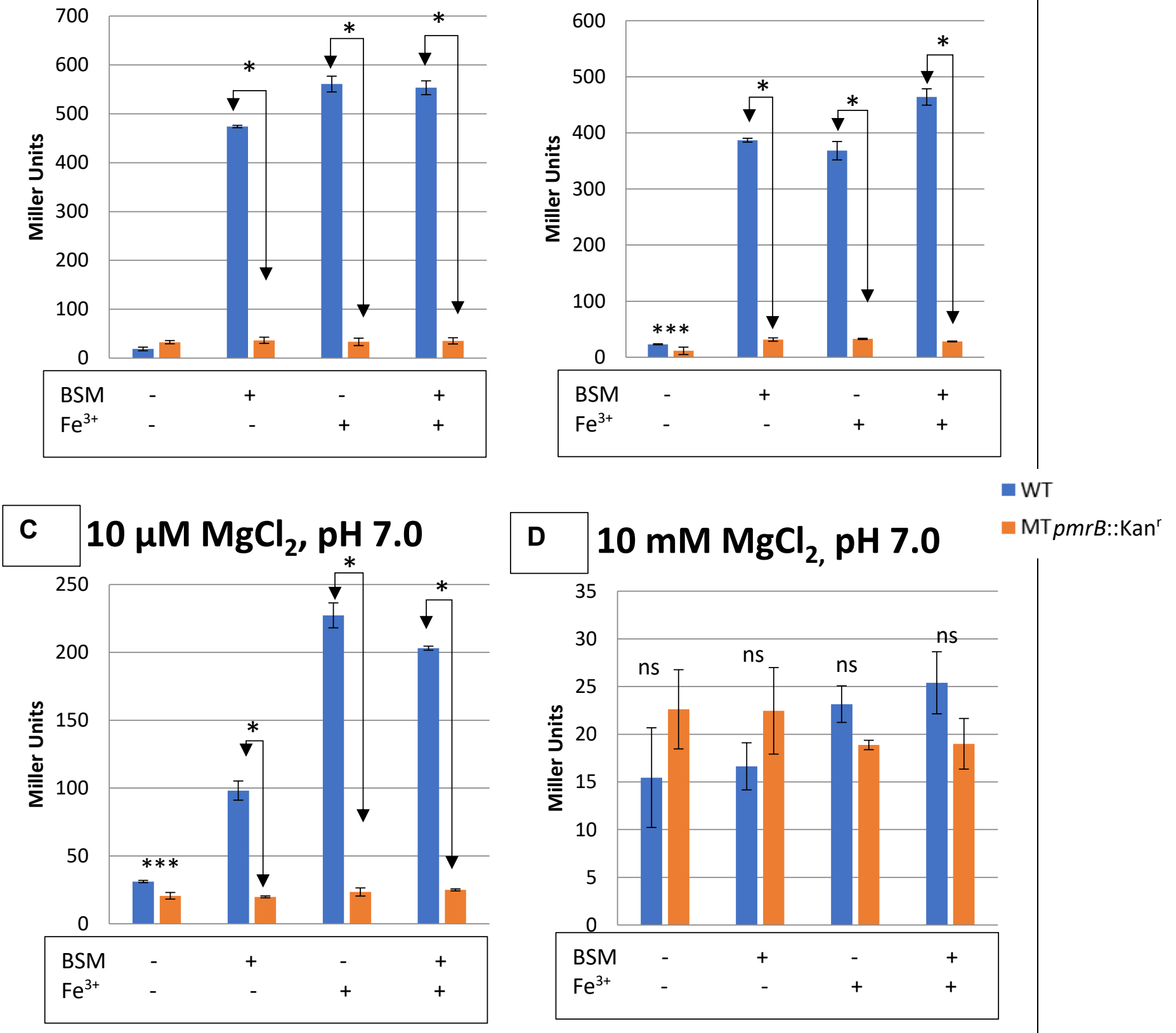

Figure 9. arnBCADTEF promoter activity in a PmrAB dependent manner $\beta$ -

Galactosidase reporter assays demonstrate EHEC promoter activity after overnight in LB broth and subculture in $10 \mu \mathrm{M} / \mathrm{mM} \mathrm{MgCl}_{2}$ at $\mathrm{pH} 5.8 / 7.0$. The activity of the promoters for arnBCADTEF were examined in $\beta$-galactosidase expression assays in both the wildtype (WT) 86-24 and pmrB::Kanr. Data shown is for 3 biological replicates $\left({ }^{* * *} p<0.005\right.$ \& ${ }^{*} p<0.0011$ ). 


\subsection{Site-directed Mutagenesis of PmrB}

The role of a conserved region, the iron-binding site of $\mathrm{PmrB}$, in EHEC survival was assessed after PMB challenge. The important amino acid, glutamate, was replaced with alanine at the $36^{\text {th }}$ position in the iron-binding motif of PmrB. The killing PMB concentrations for wt was used to assess resistance. All four sets of conditions were tested. Results shown in Figure 10 below indicate that this binding site is critical for the bile salts- and ferric iron- induced resistance. Under all magnesium and $\mathrm{pH}$ conditions, pmrBE36A was non-responsive to the presence of bile salts or ferric iron. 

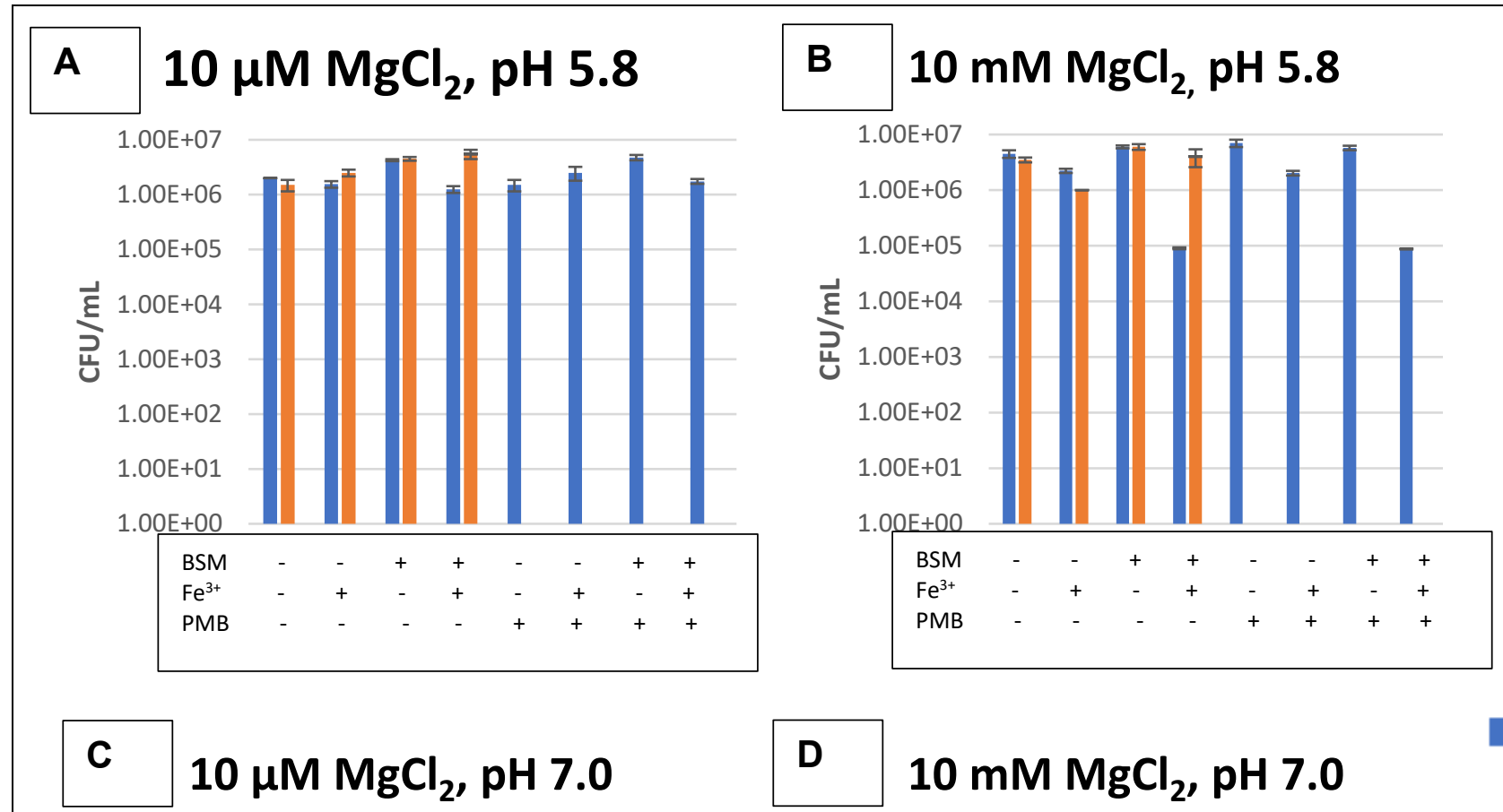

$10 \mu \mathrm{M} \mathrm{MgCl}, \mathrm{pH} 7.0$

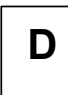

$10 \mathrm{mM} \mathrm{MgCl}, \mathrm{pH} 7.0$
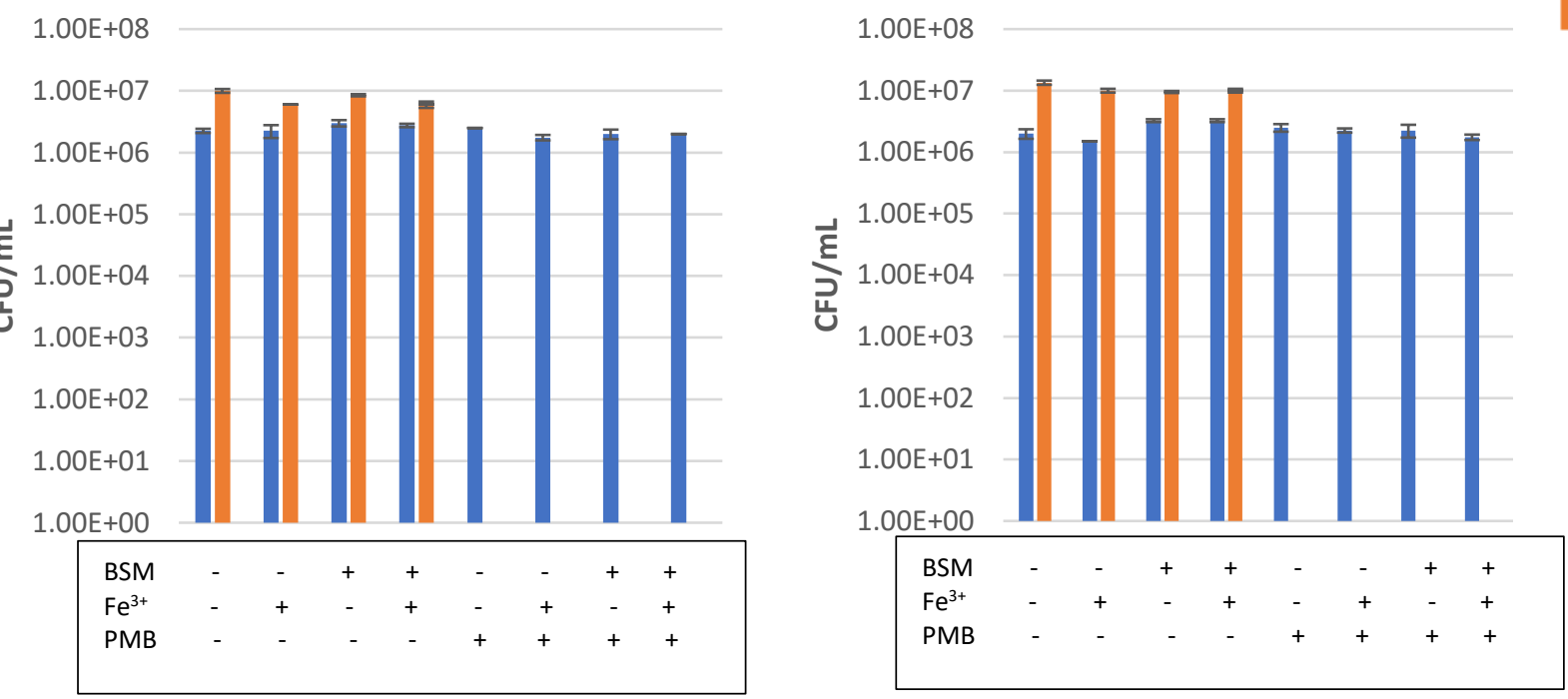

Figure 10. $\mathrm{Fe}^{3+} / \mathrm{BSM}$-induced resistance to PMB in the $\triangle p m r B E 36 A \triangle p m r B E 36 A$ was grown overnight in either $10 \mu \mathrm{M} / 10 \mathrm{mM} \mathrm{MgCl}$, $\mathrm{pH} 5.8$ or $\mathrm{pH} 7.0$ with/without 300 $\mu \mathrm{M}$ deferoxamine mesylate (+/- 1.5 \% BSM treatment) for 12-16 hours and then subcultured in the same media (+/- BSM treatment) for 4 hours, in the last hour iron chloride was added to specific conditions. Bacteria were then challenged with varying concentrations of PMB for 1 hour in a static incubator at $37^{\circ} \mathrm{C}$. Serial dilutions $\left(10^{1}-10^{4}\right.$ for $t=0$ and $10^{1}-10^{4}$ for $t=1$ ) were carried and plated. Retrievable colony counts were assessed the next day after static incubation at $37^{\circ} \mathrm{C}$ for 11 hours. Determined from 3 biological sample, 2 technical replicates $\left({ }^{*} p<0.05\right)$. 


\subsection{PmrAB and PhoPQ modulation in EHEC}

The role of bile salts and ferric iron under varying magnesium and $\mathrm{pH}$ conditions was assessed after PMB challenge. Summary Table 5 below demonstrates the importance of bile salts and ferric iron in the modulation of PmrAB, specifically under low magnesium conditions. Where, a combinatory effect of both bile salts and ferric iron under low magnesium and neutral $\mathrm{pH}$ conditions was observed. Site mutagenesis of the $36^{\text {th }}$ position on $\mathrm{PmrB}$ demonstrates a loss of function under all magnesium and $\mathrm{pH}$ conditions.

Table 5.

EHEC survival under various physiological conditions

\begin{tabular}{|c|c|c|c|c|c|c|}
\hline $\begin{array}{l}\text { Growth } \\
\text { media }\end{array}$ & $\begin{array}{c}\mathrm{Fe}^{3+} \text { killing } \\
\text { concentrations } \\
(\mu \mathrm{M})\end{array}$ & $\begin{array}{c}\text { PMB killing } \\
\text { concentrations } \\
(\mu \mathrm{g} / \mathrm{ml})\end{array}$ & $\begin{array}{l}\text { BSM induced } \\
\text { resistance }\end{array}$ & $\begin{array}{l}\mathrm{Fe}^{3+} \text { induced } \\
\text { resistance }\end{array}$ & $\begin{array}{c}\text { Combined } \\
\text { effect BSM } \\
\text { and } \mathrm{Fe}^{3+}\end{array}$ & $\begin{array}{c}\text { PmrBE } \\
36 A\end{array}$ \\
\hline $\begin{array}{l}\text { Low } \mathrm{Mg}^{2+} \text {, } \\
\text { low } \mathrm{pH}\end{array}$ & 8 & 64 & $\checkmark$ & $\checkmark$ & - & - \\
\hline $\begin{array}{l}\text { High } \mathrm{Mg}^{2+} \\
\text { low } \mathrm{pH}\end{array}$ & 8 & 32 & - & - & - & - \\
\hline $\begin{array}{l}\text { Low } \mathrm{Mg}^{2+} \text {, } \\
\text { neutral pH }\end{array}$ & 32 & 8 & $\checkmark$ & $\checkmark$ & $\begin{array}{c}\text { Showing some } \\
\text { combinatory } \\
\text { effect }\end{array}$ & - \\
\hline $\begin{array}{l}\text { High } \mathrm{Mg}^{2+} \text {, } \\
\text { neutral } \mathrm{pH}\end{array}$ & 32 & 4 & - & - & - & - \\
\hline
\end{tabular}




\section{DISCUSSION}

The colonization of EHEC in humans and other warm-blooded mammals is heavily dependent on their ability to adapt to the changing environment of the GI tract (Njoroge et al., 2012). These pathogens encounter various stressors in the GI tract such as stomach acid (Aron-Wisnewsky et al., 2012), which essentially determines their viability. Pathogenic microorganisms, however, vary in their ability to endure such stressors when factors such as length of exposure to stress are taken into account.

\subsection{Killing Concentrations of PMB higher under inducing conditions of PhoPQ and PmrAB}

The killing concentration of PMB is important clinically, as susceptibility testing for antimicrobial agents provides knowledge on treatments after bacterial infection (Peterson \& Shanholtzer, 1992). This is because it is inexpensive and is effective against many gram-negative bacteria (Duff \& Atkins, 1982). The killing concentration of PMB is the lowest concentration of PMB that will inhibit or prevent visible growth of microorganisms (Wiegand et al., 2008). Microorganisms vary in their susceptibility to antimicrobial treatment and to ensure therapeutic success, it is essential to know the concentration at which PMB will restrict pathogenic bacterial growth. The wild-type (wt) strain provides the clinically relevant inhibitory value of an antimicrobial agent which can then be used to monitor adaptive resistance in that strain (Wiegand et al., 2008). This novel study has determined the inhibitory concentrations of PMB under various physiological conditions of magnesium and $\mathrm{pH}$. 
In this present study, the killing concentrations of PMB for EHEC under varying physiological conditions of magnesium and $\mathrm{pH}$, were determined. This is the first study to do so comprehensively. It tells us about the relative roles of PhoPQ and PmrAB in PMB resistance under these different conditions. Under conditions that activate PhoPQ and PmrAB, namely low magnesium and acidic $\mathrm{pH}$, the MIC values are, not surprisingly, very high $(64 \mu \mathrm{g} / \mathrm{mL})$ of PMB. However, under conditions that only activate PhoPQ (low magnesium, neutral $\mathrm{pH}$ ), the killing concentration is lower at $32 \mu \mathrm{g} / \mathrm{mL} \mathrm{PMB}$. When conditions of neutral $\mathrm{pH}$ but high magnesium are employed, since this should not induce either PhoPQ nor PmrAB to a significant degree, it is not surprising that the MIC is even lower at $4 \mu \mathrm{g} / \mathrm{mL}$.

\subsection{Killing concentration of ferric iron largely dependent on pH}

Ferric iron at varying high concentrations can limit the growth of microorganisms (Johnson et al., 2012). This novel study identified the MIC of ferric iron for EHEC under all four sets of physiologically relevant conditions. Again, this is the first time the data has been reported for EHEC. Interestingly, it revealed that acidic $\mathrm{pH}$ reduced the $\mathrm{MIC}$ regardless of the concentration of magnesium. This likely reflects the higher solubility of ferric iron in acidic solution (Johnson et al., 2012)

\subsection{PmrAB plays an important role in EHEC's resistance to PMB}

EHEC survivability is largely dependent on its ability to recognize external stressors. It is clearly shown in this study that $p m r B$ and $p m r A$ each play a key role in PMB resistance of EHEC under both low and high magnesium and low and neutral $\mathrm{pH}$. This clearly indicates the centrality of both $p m r A$ and $p m r B$ in these responses. Since 
PhoPQ is involved at least in some of the responses (low magnesium, low $\mathrm{pH}$ ), it clearly indicates that both the sensor $p m r B$ and the response regulator pmrA are critical, even when PhoPQ is involved. This is really strong, clear data. Finally, Figure 5 demonstrates very interesting comparison, since it reveals at a finer level of distinction the relative importance of $p m r A$ and $p m r B$. Under PhoPQ and PmrAB stimulating conditions of low magnesium and low $\mathrm{pH}, \mathrm{pmrA}$ plays a more important role since the $p m r A$ mutation results in a lower killing concentration of PMB than does pmrB mutation. Given the importance of PmrA in mediating the PhoPQ signal via pmrD, this is not surprising, but the clear data is profound. This is also true under other conditions that to some degree, trigger PhoPQ-namely, Figure 3, low magnesium and neutral $\mathrm{pH}$, or high magnesium and low $\mathrm{pH}$. However, under high magnesium and high $\mathrm{pH}$, mutations in $\mathrm{pmrA}$ and pmrB have equal PMB MIC phenotypes.

\subsection{Bile salts and Ferric Iron induce PMB resistance in EHEC}

Microbial pathogens have virulence factors that are necessary for the evasion of the taxing environment of the GI tract. The production of these virulence factors has been studied extensively because it has been reported in many cases that pathogens are utilizing the resources present within the host to cue their pathogenic mechanism (Brown et al., 2008).

Chingcuanco et al (2012) has shown that acid stress enhanced the adhesion of EHEC to host intestinal epithelial cells. EHEC is therefore, utilizing the low $\mathrm{pH}$ of the stomach to upregulate genes involved in adhering to host epithelial to establish infection 
in the host (Chingcuano et al., 2012). In another study, bile salts, a component of bile, that is stored in the gall bladder and released in the small intestine, has been shown to aid in the pathogenesis of EHEC (Kus et al., 2012). Microarray analysis has shown that bile salts have cued the upregulation of genes in EHEC that resulted in enhanced resistance to PMB (Kus et al., 2012).

In this study, we have shown that either ferric iron or bile salts can induce resistance to PMB, but the results suggest that this happens only under conditions of low magnesium. The $\mathrm{pH}$ at which the assays were conducted mattered less, suggesting that either ferric iron or bile salts, which have been shown to induce CAMP resistance in a pmrAB- and arn-dependent manner, nevertheless, require the involvement at some level of PhoPQ. This was somewhat surprising since Rubin et al had reported that low $\mathrm{pH}$-induced PMB resistance was mediated through PmrAB independently of low magnesium-triggered $p m r D$ activity (Rubin et al 2015). The reason for this difference is not immediately clear. This is important new information. EHEC is in contact with these gastrointestinal stressors only transiently. However, short-term exposure to these stressors seems to be preliminary steps to cue virulence properties before final colonization in the large intestines.

\subsection{Lipid A remodeling operons upregulated via activation of PhoPQ and PmrAB}

DNA microarray analysis has shown that bile salt treatment induced the expression of genes encoding the arn operon (arnBCADTEF) and pmrAB (Kus et al., 2011). PmrAB is responsible for the recognition and transmittance of stimuli to effector 
proteins that cause the upregulation of the arn operon. When these genes are expressed, they produce as enzymes that catalyze the synthesis and transfer of LAra4N to lipid A of the bacterial LPS (Kus et al., 2011). In addition, this modification of the LPS has been shown to induce resistance in EHEC to the cationic antimicrobial peptide, PMB (Kus et al., 2011).

This work has clearly established that either ferric iron or bile salts upregulate activity of promoters for the $p m r A B$ operon and the arnBCADTEF in all conditions except high magnesium and neutral $\mathrm{pH}$ (non-regulatory conditions of both PhoPQ and PmrAB). This confirms that both ferric iron-induced PMB resistance and BSM-induced PMB resistance are mediated by the pmrAB and the arn operons. These findings, therefore, suggest that bile salts and ferric iron may have a protective effect and is an environmental cue that triggers the modification of the LPS for resistance to CAMPs.

\subsection{Induction of EHEC resistance to PMB acts through the iron-binding site on PmrB}

The iron-binding site amino acid sequence as been extensively studied in Salmonella and has been shown to respond to external ferric iron (Wosten et al., 2000). E. coli contains a PmrB homolog and has nine conserved residues, four of which serve as the iron-binding motif (Wosten et al., 2000). The iron-binding motif was shown to be imperative for recognition of ferric iron and consequently, bacteria survival decreased due to lack of responsiveness and CAMP sensitivity (Wosten et al., 2000). 
In this present study, it was shown that ferric iron and bile salts induced resistance is dependent on the iron-binding site of $\mathrm{PmrB}$ because site-directed mutagenesis at glutamic acid 36 results in complete abrogation of both ferric iron- and bile salts-induced resistance. This is the first time this has been shown and it suggests that either BSM also acts through the iron-binding site of PmrB to enhance PMB resistance or BSM serves to enhance delivery of iron within the media to the ironbinding site.

\subsection{SUMMARY AND CONCLUSION OF RESULTS}

\subsection{Summary of Results}

This study sought to examine the effect of exposure of EHEC to physiological concentrations of bile salts and ferric iron as well as observing induced resistance to CAMPs, PMB, under varying concentrations of magnesium and $\mathrm{pH}$. This study revealed the clinically relevant minimum inhibitory value of PMB for EHEC under varying physiological conditions of magnesium and $\mathrm{pH}$. It was also revealed that EHEC elicited a more pronounced resistance to $\mathrm{PMB}$ under low magnesium and neutral $\mathrm{pH}$ conditions. Interestingly, EHEC 86-24 was not resistant to PMB under high magnesium and neutral $\mathrm{pH}$ conditions. These findings suggest the important role of PhoPQ in EHEC's pathogenesis, along with PmrAB. These results were confirmed with the promoter activity assays, where increase in the expression of the promoters of pmrAB and the arn operon were non-significant under high magnesium and neutral $\mathrm{pH}$ 
conditions. This was also reiterated with bile salts or ferric iron being incapable of inducing resistance to $\mathrm{PMB}$ in a site-directed mutant of $p m r B$.

Bile salts and ferric iron have previously been shown to induce in CAMP resistance in a PmrAB dependent manner in EHEC and in E. coli respectively (Kus et al., 2011 \& Rubin et al., 2015). Based on the findings from the Rubin study (2015), it is expected that bile salt or ferric iron induction should also bypass $p m r D$, thereby not requiring it for CAMP resistance nor affecting its expression. In the current study, we report that mild acid induces significant EHEC resistance to PMB regardless of the presence of limiting magnesium which is consistent with Rubin et al. However, our results also suggest that limiting magnesium enhances the induction of resistance by each of bile salts and ferric iron, suggesting that PhoPQ plays at least a partial role in the induction of resistance by ferric iron and bile salts. This would suggest that pmrD would play a partial role in bile salt and ferric iron induced PMB resistance, which would not be consistent with the findings of Rubin et al. The reason for this difference is not immediately evident and deserves further investigation. Finally, interestingly, our study indicates that bile salts and ferric iron both stimulate PmrB (BasS) mediated changes through the same iron binding site on PmrA which suggests that either bile salts acts through the same site on PmrB or that bile salts may be enhancing the solubility or delivery of iron to PmrB. Once again, this finding certainly deserves further study. 


\subsection{Future Work}

Future studies could further explore and evaluate the mechanism of bile saltinduced pmrAB mediated CAMP resistance of EHEC through the iron binding motif and secondly, it would be valuable to carry out a comparative analysis of resistance to Human defensin-5 (HD-5) and other CAMPs. The pmrD and phoP deficient EHEC strains would be useful in understanding the role these genes play in bile salt and ferric iron induced CAMP resistance. These results would add to our understanding of the role of host innate immune defences in relation to EHEC fitness and pathogenesis. It would also provide further insight into how EHEC uses host microenvironmental cues to enhance fitness and survival in the hostile environment of the host GI tract.

\subsection{Significance and Conclusion}

Diarrheagenic microorganisms that infect the mammalian gastrointestinal tract have to overcome stressors within the environment to establish colonization at their specific sites. These results show that the conditions in the GI tract serve as environmental cues for virulence properties in EHEC 86-24. This study demonstrates, for the first time, the minimum concentration of PMB and ferric iron that will inhibit the growth of EHEC 86-24 under various magnesium and $\mathrm{pH}$ conditions. Bile salts and ferric iron were shown to be triggers of pmrAB and aided in EHEC's pathogenesis by inducing resistance to PMB. These findings also demonstrated that CAMP resistance is largely modulated by two component systems, PhoPQ and PmrAB. These two component systems work together in order progress with lipid A remodeling and consequently, CAMP resistance. 
This work contributes to knowledge about what facilitates pathogenic infection and therefore, opens the door for pursuing agents that can effectively combat pathogenic infection. 


\section{REFERENCES}

Aron-Wisnewsky, J., Doré, J., \& Clement, K. (2012). The importance of the gut microbiota after bariatric surgery. Nature Reviews Gastroenterology and Hepatology, 9(10), 590-598.

Asano, Y., Karasudani, T., Tanaka, H., Matsumoto, J., Okada, M., Nakamura, K., Shinomiya, H. (2013). Characterization of the Escherichia coli O157:H7 outbreak strain whose shiga toxin 2 gene is inactivated by IS1203v insertion. Japanese Journal of Infectious Diseases, 66(3), 201-206.

Begley, M., Gahan, C. G., \& Hill, C. (2005). The interaction between bacteria and bile. FEMS Microbiology Review, 29, 625-651.

Bergan, J., Dyve Lingelem, A. B., Simm, R., Skotland, T., \& Sandvig, K. (2012). Shiga toxins. Toxicon, 60(6), 1085-1107.

Binder, H. J., Filburn, B., \& Floch, M. (1975). Bile acid inhibition of intestinal anaerobic organisms. American Journal of Clinical Nutrition, 28(2), 119-125.

Bradshaw, J. P. (2003). Cationic antimicrobial peptides: Issues for potential clinical use. BioDrugs, 17(4), 233-240.

Brown, S. P., Le Chat, L., \& Taddei, F. (2008). Evolution of virulence: Triggering host inflammation allows invading pathogens to exclude competitors. Ecology Letters, 11(1), 44-51.

Bugarel, M., Martin, A., Fach, P., \& Beutin, L. (2011). Virulence gene profiling of enterohemorrhagic (EHEC) and enteropathogenic (EPEC) Escherichia coli strains: 
A basis for molecular risk assessment of typical and atypical EPEC strains. BMC Microbiology, 11.

Casadaban M. J., Chou J., Cohen S. N. (1980). In vitro gene fusions that join an enzymatically active beta-galactosidase segment to amino-terminal fragments of exogenous proteins: Escherichia coliplasmid vectors for the detection and cloning of translational initiation signals. Journal of Bacteriology, 143, 971-980.

Cavaillon , J. (2011). Polymyxin B for endotoxin removal in sepsis. Lancet: Infectious Diseases, 11(6), 426-427.

Cherayil, B. J. (2011). The role of iron in the immune response to bacterial infection. Immunologic Research,50(1), 1-9.

Chingcuanco, F., Yu, Y., Kus, J. V., Que, L., Lackraj, T., Lévesque, C. M., \& Barnett Foster, D. (2012). Identification of a novel adhesin involved in acid-induced adhesion of enterohaemorrhagic Escherichia coli 0157:H7. Microbiology (United Kingdom), 158(9), 2399-2407.

Cleary, J., Lai, L. Shaw, R. K., Straatman-Iwanowska, A., Donneberg, M. S., Frankel, G., \& Knutton, S. (2004). Enteropathogenic Escherichia coli (EPEC) adhesion to intestinal epithelial cells: Role of bundle-forming pili (BFP), EspA filaments and intimin. Microbiology, 150(3), 527-538.

Dahl, J., Koldewey, P., Salmon, L., Horowitz, S., Bardwell, J. C. A., \& Jakob, U. (2015). HdeB functions as an acid-protective chaperone in bacteria. Journal of Biological Chemistry, 290(1), 65-75. 
Duff, G. W., \& Atkins, E. (1982). The inhibitory effect of polymyxin B on endotoxininduced endogenous pyrogen production. Journal of Immunological Methods, 52(3), 333-340.

Edwards, R. A., Keller, L. H., \& Schifferli, D. M. (1998). Improved allelic exchange vectors and their use to analyze 987P fimbria gene expression. Gene, 207(2), 14957.

Gadishaw-Lue, C. (2015). Bile salts differentially enhance resistance of enterohemorrhagic Esherchia coli $\mathrm{O} 157: \mathrm{H} 7$ to human cationic antimicrobial peptides (Master's Thesis). Department of Chemistry and Biology, Ryerson University.

Griffin P. M., et al (1988). Illnesses associated with Escherichia coliO157:H7 infections. A broad clinical spectrum. Ann. Intern. Med. 109, 705-712.

Gunn, J. S. (2000). Mechanisms of bacterial resistance and response to bile. Microbes and Infection, 2, 907-913.

Hancock, R. E. W., \& Diamond, G. (2000). The role of cationic antimicrobial peptides in innate host defences. Trends in Microbiology, 8(9), 402-410.

Hofmann, A. F., \& Eckmann, L. (2006). How bile acids confer gut mucosal protection against bacteria. Proceedings of the National Academy of Sciences of the United States of America, 103(12), 4333-4334.

Hyytiäinen, H., Sjöblom, S., Palomäki, T., Tuikkala, A., \& Palva, E. T. (2003). The PmrA-PmrB two-component system responding to acidic $\mathrm{pH}$ and iron controls 
virulence in the plant pathogen Erwinia carotovora ssp. carotovora. Molecular Microbiology, 50(3), 795-807.

Izadpanah, A., \& Gallo, R. L. (2005). Antimicrobial peptides. Journal of the American Academy of Dermatology, 52(3 Pt 1), 381-390.

Johnson, D. B., Kanao, T., \& Hedrich, S. (2012). Redox Transformations of Iron at Extremely Low pH: Fundamental and Applied Aspects. Frontiers in Microbiology, 3, 96.

Kaper, J. B., Nataro, J. P., \& Mobley, H. L. T. (2004). Pathogenic Escherichia coli. Nature Reviews.Microbiology, 2(2), 123-40.

Kaper, J. B., \& Sperandio, V. (2005). Bacterial cell-to-cell signaling in the gastrointestinal tract. Infection and Immunity, 73(6), 3197-3209.

Kistemann, T., Zimmer, S., Vågsholm, I., \& Andersson, Y. (2004). GIS-supported investigation of human EHEC and cattle VTEC 0157 infections in sweden: Geographical distribution, spatial variation and possible risk factors. Epidemiology and Infection, 132(3), 495-505.

Kohgo, Y., Ikuta, K., Ohtake, T., Torimoto, Y., \& Kato, J. (2008). Body iron metabolism and pathophysiology of iron overload. International Journal of Hematology, 88(1), $7-15$.

Koretke, K. K., Lupas, A. N., Warren, P. V., Rosenberg, M., \& Brown, J. R. (2000). Evolution of two-component signal transduction. Molecular Biology and Evolution, 17(12), 1956-1970. 
Kortman, G. A. M., Boleij, A., Swinkels, D. W., \& Tjalsma, H. (2012). Iron availability increases the pathogenic potential of Salmonella typhimurium and other enteric pathogens at the intestinal epithelial interface. PLOS ONE, 7(1).

Kus, J. V., Gebremedhin, A., Dang, V., Tran, S., Serbanescu, A., \& Barnett Foster, D. (2011). Bile salts induce resistance to polymyxin in enterohemorrhagic Escherichia coli O157:H7. Journal of Bacteriology, 193(17), 4509-4515.

Lentz, E. K., Leyva-Illades, D., Lee, M., Cherla, R. P., \& Tesh, V. L. (2011). Differential response of the human renal proximal tubular epithelial cell line HK-2 to shiga toxin types 1 and 2. Infection and Immunity, 79(9), 3527-3540.

Lusk, J. E., Williams, R. J. P., \& Kennedy, E. P. (1968). Magnesium and the Growth of Escherichia coli. The Journal of Biological Chemistry, 243(10), 2618-2624.

Merritt, M. E., \& Donaldson, J. R. (2009). Effect of bile salts on the DNA and membrane integrity of enteric bacteria. Journal of Medical Microbiology, 58(12), 1533-1541.

Monte, M. J., Marin, J. J., Antelo, A., \& Vazquez-Tato, J. (2009). Bile acids: Chemistry, physiology, and pathophysiology. World Journal of Gastroenterology: WJG, 15(7), 804-816.

Moskowitz, S. M., Ernst, R. K., \& Miller, S. I. (2004). PmrAB, a Two-Component Regulatory System of Psedomonas aeruginosa That Modulates Resistance to Cationic Antimicrobial Peptides and Addition of Aminoarabinose to Lipid A, Journal of Bacteriology, 186(2), 575-579. 
Mueller, C. A., Broz, P., \& Cornelis, G. R. (2008). The type III secretion system tip complex and translocon. Molecular Microbiology, 68(5), 1085-1095.

Nataro, J. P., \& Kaper, J. B. (1998). Diarrheagenic Escherichia coli. Clinical Microbiology Reviews, 11(1), 142-201.

Nguyen, Y., \& Sperandio, V. (2012). Enterohemorrhagic E. coli (EHEC) pathogenesis. Frontiers in Cellular and Infection Microbiology, 2, 90.

Nixon, T. B., Ronson, C. W., \& Ausubel, F. M. (1986). Two-component regulatory systems responsive to environmental stimuli share strongly conserved domains with the nitrogen assimilation regulatory genes ntrB and ntrC. Proc. Natl. Acad. Sci., 83, 7850-7854.

Njoroge, J. W., Nguyen, Y., Curtis, M. M., Moreira, C. G., \& Sperandio, V. (2012). Virulence meets metabolism: Cra and $\mathrm{KdpE}$ gene regulation in enterohemorrhagic Escherichia coli. MBio, 3(5).

Ouellette, A. J. (2011). Paneth Cell $\alpha$-Defensins in Enteric Innate Immunity. Cellular and Molecular Life Sciences: CMLS, 68(13), 2215-2229.

Peterson, L. R., \& Shanholtzer, C. J. (1992). Tests for bactericidal effects of antimicrobial agents: technical performance and clinical relevance. Clinical Microbiology Reviews, 5(4), 420-432.

Raetz, C. R., Reynolds, C. M., Trent, M. S., \& Bishop, R. E. (2007). Lipid A Modification Systems in Gram-negative Bacteria. Annual Review of Biochemistry, 76, 295-329. 
Rubin, E., Herrera, C., Crofts, A., \& Trent, S. (2015). PmrD Is required for Modifications to Escherichia coli Endotoxin That Promote Antimicrobial Resistance. Antimicrobial Agents and Chemotherapy, 59, 2051-2061.

Schneider, J. J., Unholzer, A., Schaller, M., Schäfer-Korting, M., \& Korting, H. C. (2005). Human defensins. Journal of Molecular Medicine, 83(8), 587-595.

Schüller, S. (2011). Shiga toxin interaction with human intestinal epithelium. Toxins, 3(6), 626-639.

Shuman, S. (1991). Recombination mediated by vaccinia virus DNA topoisomerase I in Escherichia coli is sequence specific. Proceedings of the National Academy of Sciences of the United States of America, 88(22), 10104-10108.

Skaar, E. P. (2010). The battle for iron between bacterial pathogens and their vertebrate hosts. PLoS Pathogens, 6(8), 1-2.

Smet, K. D., \& Contreras, R. (2005). Human Antimicrobial Peptides: Defensins, Cathelicidins and Histatins, Biotechnology Letters, 27(18), 1337-1347.

The Crankshaft Publishing. (no date). Infections Due to Escherichia Coli and Other Enteric Gram-Negative Bacilli Part 1. In what-when-how. Retrieved March 25, 2014, from http://what-when-how.com/acp-medicine/infections-due-to-escherichiacoli-and-other-enteric-gram-negative-bacilli-part-1/.

Thomassin, J., Lee, M. J., Brannon, J. R., Sheppard, D. C., Gruenheid, S., \& Le Moual, H. (2013). Both group 4 capsule and lipopolysaccharide O-antigen contribute to 
enteropathogenic Escherichia coli resistance to human a-defensin 5. PLOS ONE, $8(12)$.

Trent, M. S., Ribeiro, A. A., Lin, S., Cotter, R. J., \& Raetz, C. R. (2001). An inner membrane enzyme in Salmonella and Escherichia coli that transfers 4-amino-4deoxy-L-arabinose to Lipid A: induction on polymyxin-resistant mutants and role of a novel lipid-linked donor. J Biol Chem, 276(46), 43122-43131.

Vallance, B.A. and Finlay, B.B. (2000). Exploitation of host cells by enteropathogenic Escherichia coli. PNAS, 97, 8799-8806.

Wagner, P. L., Acheson, D. W. K., \& Waldor, M. K. (2001). Human neutrophils and their products induce shiga toxin production by enterohemorrhagic Escherichia coli. Infection and Immunity, 69(3), 1934-1937.

WHO. (2011). Public health review of the Enterohemorrhagic Escherichia coli Fact Sheet. Regional Office for Europe. World Health Organization.

Wong, A. R. C., Pearson, J. S., Bright, M. D., Munera, D., Robinson, K. S., Lee, S. F., Hartland, E. L. (2011). Enteropathogenic and enterohaemorrhagic Escherichia coli: Even more subversive elements. Molecular Microbiology, 80(6), 1420-1438.

Wösten, M. M. S. M., Kox, L. F. F., Chamnongpol, S., Soncini, F. C., \& Groisman, E. A. (2000). A signal transduction system that responds to extracellular iron. Cell, 103(1), $113-125$ 
Xu, X., McAteer, S. P., Tree, J. J., Shaw, D. J., Wolfson, E. B. K., Beatson, S. A., Gally, D. L. (2012). Lysogeny with shiga toxin 2-encoding bacteriophages represses type III secretion in enterohemorrhagic Escherichia coli. PLoS Pathogens, 8(5).

Yan, A., Guan, Z., \& Raetz, C. R. (2007). An Undecaprenyl Phosphate-Aminoarabinose Flippase required for Polymyxin Resistance in Escherichia coli. J Biol Chem, 282(49), 36077-36089.

Zhang, Y., Cougnon, F. B. L., Wanniarachchi, Y. A., Hayden, J. A., \& Nolan, E. M. (2013). Reduction of human defensin 5 affords a high-affinity zinc-chelating peptide. ACS Chemical Biology, 8(9), 1907-1911. 